\title{
Research Square \\ Theoretical and Experimental Studies of ion Transport in Mixed Polyanion Solid Electrolytes
}

\section{Zeyu Deng}

National University of Singapore https://orcid.org/0000-0003-0109-9367

\section{Tara Mishra}

National University of Singapore

\section{Eunike Mahayoni}

Université de Picardie Jules Verne

\section{Qianli Ma}

Forschungszentrum Jülich https://orcid.org/0000-0002-4709-4927

\section{Olivier Guillon}

Forschungszentrum Juelich $\mathrm{GmbH}$, Institute of Energy and Climate Research IEK-1

\section{Jean-Noel Chotard}

University of Picardie Jules Verne https://orcid.org/0000-0002-9867-7954

\section{Vincent Seznec}

https://orcid.org/0000-0001-5233-5943

\section{Anthony K. Cheetham}

University of Cambridge https://orcid.org/0000-0003-1518-4845

\section{Christian Masquelier}

Univ. Picardie Jules Verne

\section{Gopalakrishnan Sai Gautam}

Massachusetts Institute of Technology https://orcid.org/0000-0002-1303-0976

Pieremanuele Canepa ( $\sim$ pcanepa@nus.edu.sg )

National University of Singapore https://orcid.org/0000-0002-5168-9253

\section{Article}

Keywords: ion transport, polyanion mixing, NASICON

Posted Date: December 1st, 2021

DOI: https://doi.org/10.21203/rs.3.rs-1102507/v1

License: (c) (i) This work is licensed under a Creative Commons Attribution 4.0 International License. Read Full License 
Version of Record: A version of this preprint was published at Nature Communications on August 2nd, 2022. See the published version at https://doi.org/10.1038/s41467-022-32190-7. 


\title{
Theoretical and Experimental Studies of ion Transport in Mixed Polyanion Solid Electrolytes
}

\author{
Zeyu Deng, ${ }^{1 *}$ Tara P. Mishra, ${ }^{1,2}$ Eunike Mahayoni, ${ }^{3,4,5}$ Qianli Ma, ${ }^{6}$ Olivier Guillon,, 67 \\ Jean-Noël Chotard, ${ }^{3,4,5}$ Vincent Seznec, ${ }^{3,4,5}$ Anthony K. Cheetham, ${ }^{1}$ Christian \\ Masquelier ${ }^{3,4,5}$ Gopalakrishnan Sai Gautam, ${ }^{8}$ and Pieremanuele Canepa ${ }^{1,2,9}$ \#
}

${ }^{1}$ Department of Materials Science and Engineering, National University of Singapore, Singapore 117575, Singapore

${ }^{2}$ Singapore-MIT Alliance for Research and Technology, 1 CREATE Way, 10-01 CREATE Tower, Singapore 138602, Singapore

${ }^{3}$ Laboratoire de Réactivité et de Chimie des Solides (LRCS), CNRS UMR 7314, Université de Picardie Jules Verne, 80039 Amiens Cedex, France.

${ }^{4}$ RS2E, Réseau Français sur le Stockage Electrochimique de l'Energie, FR CNRS 3459, F-80039 Amiens Cedex 1, France.

${ }^{5}$ ALISTORE-ERI European Research Institute, FR CNRS 3104, Amiens, F-80039 Cedex 1, France.

${ }^{6}$ Forschungszentrum Jülich $\mathrm{GmbH}$, Institute of Energy and Climate Research, Materials Synthesis and Processing (IEK-1), 52425 Jülich, Germany

${ }^{7}$ Helmholtz-Institute Münster, c/o Forschungszentrum Jülich $\mathrm{GmbH}, 52425$ Jülich, Germany ${ }^{8}$ Department of Materials Engineering, Indian Institute of Science, Bengaluru, 560012, Karnataka, India

${ }^{9}$ Chemical and Biomolecular Engineering, National University of Singapore, 4 Engineering Drive 4, Singapore, 117585, Singapore.

Corresponding authors: *msedz@nus.edu.sg and \#pcanepa@nus.edu.sg 


\section{Abstract}

Lithium and sodium ( $\mathrm{Na}$ ) mixed polyanion solid electrolytes for all-solid-state batteries display some of the highest ionic conductivities reported to date. However, the effect of polyanion mixing on ion transport properties is still debated. Here, we focus on $\mathrm{Na}_{1+x} \mathrm{Zr}_{2} \mathrm{Si}_{x} \mathrm{P}_{3-x} \mathrm{O}_{12}(0 \leq x \leq 3)$ NASICON electrolyte to elucidate the role of polyanion mixing on Na-transport properties. Although there is a large body of data available on this NASICON system, transport properties extracted from experiments or theory vary by orders of magnitude, signifying the need to bridge the gap between different studies. Here, more than 2,000 distinct ab initio-based kinetic Monte Carlo simulations have been used to map the statistically vast compositional space of NASICON over an unprecedented time range and spatial resolution and across a range of temperatures. We performed impedance spectroscopy of samples with varying $\mathrm{Na}$ compositions revealing that the highest ionic conductivity $\left(\sim 0.1 \mathrm{~S} \mathrm{~cm}^{-1}\right)$ is achieved in $\mathrm{Na} 3.4 \mathrm{Zr}_{2} \mathrm{Si}_{2.4} \mathrm{P}_{0.6} \mathrm{O}_{12}$, in line with our predictions $\left(\sim 0.2 \mathrm{~S} \mathrm{~cm}^{-1}\right)$. Our predictions indicate that suitably doped NASICON compositions, especially with high silicon content, can achieve high $\mathrm{Na}^{+}$mobilities. Our findings are relevant for the optimization of mixed polyanion solid electrolytes and electrodes, including sulfide-based polyanion frameworks, which are known for their superior ionic conductivities. 


\section{Introduction}

The reliability of rechargeable batteries and other energy storage devices depends on the fast delivery of ions between electrodes..$^{1-4}$ In rechargeable batteries, the safety and performance of electrolytes are as important as other battery components, such as electrodes. Solid-state batteries, where liquid electrolytes are replaced by solid fastion conductors, offer a promising pathway for safer commercial lithium-ion and prototypical sodium (Na)-ion batteries. ${ }^{4-6}$ Several solid electrolytes, such as the LiSiCON-type $\mathrm{Li}_{4 \pm x} \mathrm{Si}_{1-\mathrm{x}} \mathrm{Z}_{\times} \mathrm{O}_{4}\left(\mathrm{Z}=\mathrm{P}^{5+}, \mathrm{Al}^{3+}, \mathrm{Sn}^{4+}\right.$ and/or $\left.\mathrm{Ge}^{4+}\right),{ }^{7,8} \mathrm{Li}_{10 \mathrm{MP}} \mathrm{S}_{12}$ made from $\mathrm{Li}_{4} \mathrm{MS}_{4}: \mathrm{Li}_{3} \mathrm{PS}_{4}\left(\mathrm{M}=\mathrm{Ge}^{4+}, \mathrm{Sn}^{4+}\right.$, and $\left.\mathrm{Si}^{4+}\right),{ }^{9-16}$ and $\mathrm{Na}_{1+x} \mathrm{Zr}_{2} \mathrm{Si}_{x} \mathrm{P}_{3-\mathrm{x}} \mathrm{O}_{12}$ (hereafter referred as NASICON), ${ }^{17-19}$ leverage mixed polyanion frameworks to attain some of the highest ionic conductivities $(\approx 10 \mathrm{mS} / \mathrm{cm})$ reported so far. ${ }^{4}$

Ion transport in mixed polyanion solid electrolytes has been investigated using

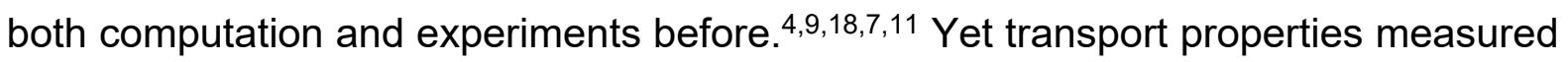
from different techniques typically vary by orders of magnitude.$^{20}$ On one hand, averaged transport properties obtained from experiments, such as impedance spectroscopy, solid-state nuclear magnetic resonance, and quasi-elastic neutron scattering, ${ }^{4,6,16,21}$ may incorporate effects arising from defects and grain boundaries. ${ }^{22}$ On the other hand, classical or ab initio molecular dynamics (MD) studies perform "one shot" simulations on selected bulk structures, which may not be sufficiently representative in terms of longer time-scale transport processes as well as in the number of possible arrangements of different polyanions. ${ }^{2,3,23-25}$ Thus, there is a need to reconcile the measurements and simulations to guide the development and manufacturing of the next generation of solid electrolytes and their batteries.

In this study, we have selected the NASICON Na ${ }_{1+x} \mathrm{Zr}_{2} \mathrm{Si}_{x} \mathrm{P}_{3-x} \mathrm{O}_{12}(0 \leq x \leq 3)$ electrolyte as an example to elucidate the role of polyanion mixing on the macroscopic 
transport properties, including ionic diffusivity and conductivity. The choice of NASICON is justified by the large body of data available on this system since its discovery more than 40 years ago, ${ }^{17,18,26-29}$ making it easier to reconcile previous experimental and computational studies.

To capture the large statistical variance in transport properties introduced by mixed polyanions in NASICON samples, we developed a high-fidelity kinetic Monte Carlo (kMC) model bearing the accuracy of density functional theory (DFT) calculations. More than 2,000 distinct kMC simulations served to map the statistically vast compositional space of $\mathrm{Na}_{1+x} \mathrm{Zr}_{2} \mathrm{Si}_{x} \mathrm{P}_{3-x} \mathrm{O}_{12}$ over an unprecedented time range in the realm of milliseconds - and spatial resolution, with varying temperature.

First of all, our model reproduces existing measurements of Na-transport properties in NASICON, suggesting that a robust sampling of both the spatial and temporal axes is required in computations to accurately estimate these properties. The reproduction of measured Na-transport properties in NASICON also implies that our model correctly captures the collective nature of Na-transport, which is responsible for the high ionic conductivity observed in NASICON. Second, our simulations elucidate the impact of the thermodynamic forces driving the random distribution of $\mathrm{PO}_{4}{ }^{3-}$ and $\mathrm{SiO}_{4}{ }^{4-}$ groups in NASICON during synthesis (and subsequent thermal treatment) on the Na-ion transport. Third, our statistical insights can guide the selection of optimal doping and thermal treatment strategies to further improve the properties of NASICON electrolytes. For example, our analysis suggests that higher $\mathrm{Na}^{+}$conductivity in NASICON can be achieved by increasing the content of $\mathrm{SiO}_{4}{ }^{4-}$ units in place of $\mathrm{PO}_{4}{ }^{3-}$ moieties, while maintaining high $\mathrm{Na}$ content in the structure. Motivated by our computational findings, we have also synthesized and characterized selected compositions of the NASICON, which validates our predictions. These findings, 
elaborated on NASICON electrolytes, are general and transferable to the study of ionic transport in other topical mixed-polyanion $\mathrm{Li}$ and $\mathrm{Na}$ solid electrolytes. 


\section{Results}

Figure 1a depicts the crystal structure of NASICON, where red $\mathrm{SiO}_{4} / \mathrm{PO}_{4}$ tetrahedra share corners with two blue $\mathrm{ZrO}_{6}$ octahedra forming the so-called "lantern units". In the rhombohedral high-temperature NASICON structure $(R \overline{3} c)$, there are two independent and partially occupied sodium sites, $\mathrm{Na}(1)$ and $\mathrm{Na}(2)$. The partial occupancy of these sites gives rise to the well-known high ionic conductivity in NASICON. A third interstitial $\mathrm{Na}$ site, known as $\mathrm{Na}(3)$, adjacent to $\mathrm{Na}(1)$ and $\mathrm{Na}(2)$ has been previously considered. ${ }^{30,31}$ However, Zhang et al. ${ }^{32}$ showed that $\mathrm{Na}(3)$ is negligibly occupied over a wide range of temperatures $\left(200<\mathrm{T}<800{ }^{\circ} \mathrm{C}\right)$ and less relevant for Na-transport in NASICON. The structural images in Figure $\mathbf{1 b}$ and $\mathbf{c}$ emphasize the $\mathrm{Na}(1)$ sites, with their neighboring $\mathrm{Na}$ (2) (orange spheres) and $\mathrm{Si} / \mathrm{P}$ (red spheres) sites, resulting in distorted hexagonal prisms (silver). For visualization purposes, Figure $\mathbf{1 b}$ and $\mathbf{c}$ omit the $\mathrm{Zr}$ and $\mathrm{O}$ atoms. 

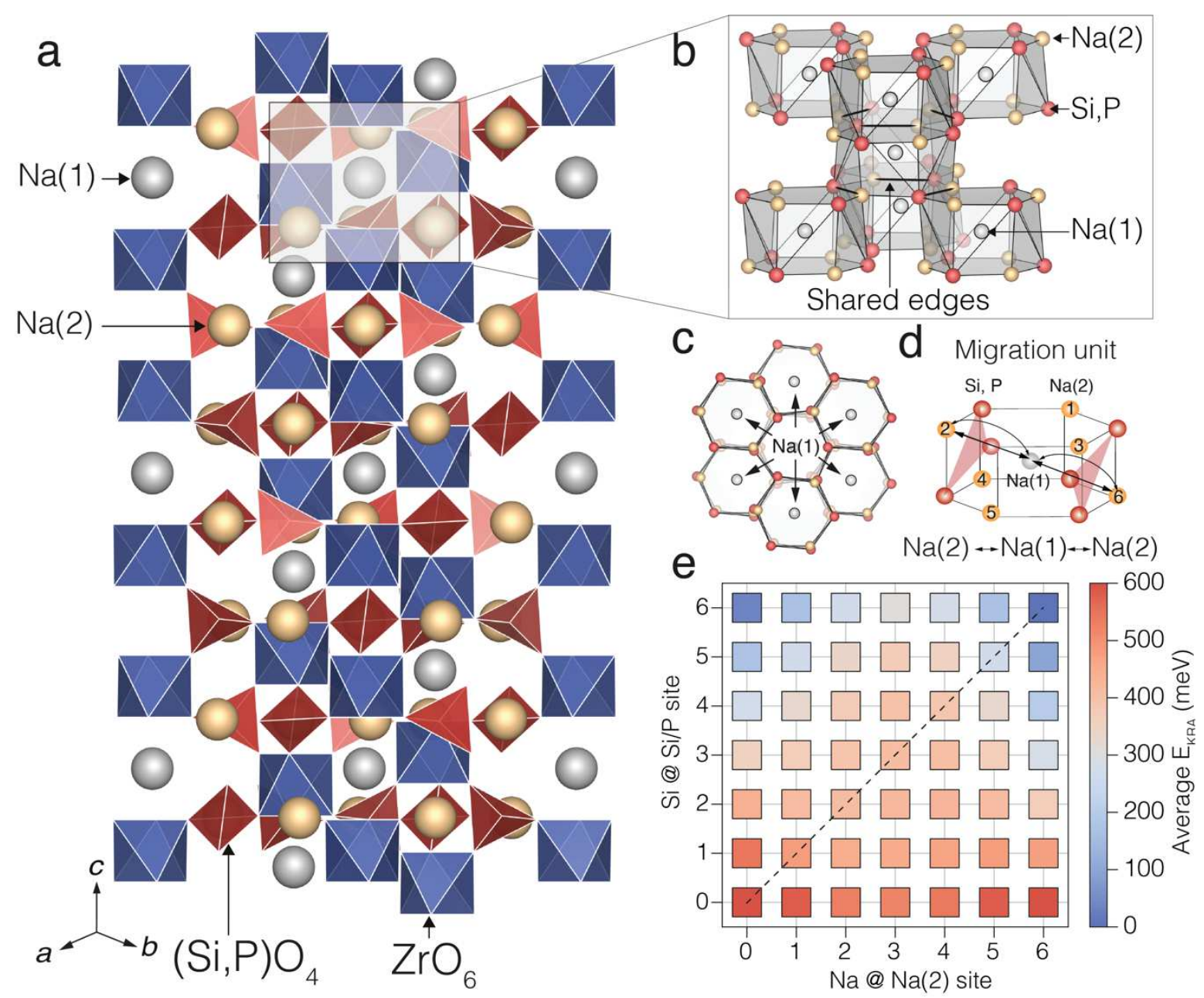

Figure 1 | Characteristics of sodium ion transport in NASICON. Structural models of $\mathrm{Na}_{1+\times} \mathrm{Zr}_{2} \mathrm{Si}_{x} \mathrm{P}_{3-\mathrm{x}} \mathrm{O}_{12}(\mathbf{a}, \mathbf{b}, \mathbf{c}$, and $\mathbf{d})$ and Na-migration barriers (e). In a, b, c and $\mathbf{d}$, the $\mathrm{Na}(1)$ sites are indicated by silver spheres, the $\mathrm{Na}(2)$ by orange spheres, the $(\mathrm{Si} / \mathrm{P}) \mathrm{O}_{4}$ groups by red tetrahedra, Si/P atoms by red spheres, and $\mathrm{ZrO}_{6}$ units by blue octahedra. $\mathbf{b}$ and $\mathbf{c}$ depict the local environment of $\mathrm{Na}(1)$, with each $\mathrm{Na}(1)$ surrounded by six neighboring $\mathrm{Na}(2)$ atoms (orange spheres) and six Si/P (red spheres) atoms. For simplicity, $\mathrm{O}$ and $\mathrm{Zr}$ atoms are not shown in $\mathbf{b}, \mathbf{c}$, and $\mathbf{d}$. Each silver hexagonal prism in $\mathbf{b}$ or $\mathbf{c}$ represents the first coordination shell of a $\mathrm{Na}(1)$ site. Panel $\mathbf{d}$ is the migration unit used to study Na-migration in NASICON, and Na must hop across several different migration units to ensure Na diffusion. Red triangles in $\mathbf{d}$ indicate the bottlenecks caused by Si/ $\mathrm{PO}_{4}$ tetrahedra (oxygen atoms are not shown). e shows the averaged kinetically resolved activation (KRA) barriers for $\mathrm{Na}(2) \leftrightarrow \mathrm{Na}$ (1) hops, with varying $\mathrm{Na}(2)$ site occupation and Si/P content per migration unit. The barriers were extracted from a local cluster expansion model, which was fitted to the calculated nudged elastic band (NEB) barriers. The diagonal line in e shows locally charge neutral Si/P configurations. The computed NEB barriers used for fitting to generate the heatmap in e are available in the supporting information (SI). 
Figure 1d shows the smallest relevant unit -the migration unit- encompassing all possible migration events for $\mathrm{Na}$-ions in NASICON. The migration unit centered around $\mathrm{Na}(1)$ highlights the connectivity between the $\mathrm{Na}(1)$ site and its closest six $\mathrm{Na}(2)$ neighbor sites, as well as the neighboring $\mathrm{Si}(\mathrm{P})$ atoms. Each migration unit (see Figure $\mathbf{1 b}$ and $\mathbf{c}$ ) is edge-shared with six neighboring migration units, where each unit can exhibit its own distribution of Na/vacancies and Si/P. In the NASICON structure, Na-transport must always involve both $\mathrm{Na}(1)$ and $\mathrm{Na}(2)$ sites, ${ }^{18,30,33,34}$ giving rise to migration pathways of the kind $\mathrm{Na}(1) \leftrightarrow \mathrm{Na}(2)$. The specific Na-migration pathway depends entirely on the $\mathrm{Na}$ and Si/P content within the structure, ${ }^{19,30,31}$ which sets the occupation and the relative stability of $\mathrm{Na}(1)$ and $\mathrm{Na}(2)$ sites. For example, at low $\mathrm{Na}$ content $(x=0), \mathrm{Na}$ ions reside only in $\mathrm{Na}(1)$ sites, favoring a $\mathrm{Na}(1) \leftrightarrow \mathrm{Na}(2) \leftrightarrow \mathrm{Na}(1)$ pathway. ${ }^{17,30,32}$ At higher $\mathrm{Na}$ content $(\mathrm{x} \geq 2)$, both $\mathrm{Na}(1)$ and $\mathrm{Na}(2)$ sites are occupied to varying degrees (see later Figure 2), and any of the two migration pathways can be active. ${ }^{19,30}$ Importantly, for macroscopic Na diffusion to occur in NASICON, several successful migration hopping events, between adjacent migration units, need to happen, for which it is critical that $\mathrm{Na}$ atoms can hop from $\mathrm{Na}(1)$ to $\mathrm{Na}(2)$ sites (or viceversa) within each unit. Thus, we considered a single migration event to be $\mathrm{Na}(1) \leftrightarrow$ $\mathrm{Na}(2)$ within a single migration unit, in the presence of varying $\mathrm{Na}$ and Si/P content.

For any $\mathrm{Na}$ composition in the range $0 \leq \mathrm{x} \leq 3$, the concentrations of $\mathrm{Si}$, and $\mathrm{P}$ are set by the NASICON stoichiometry, such that the composition guarantees global charge neutrality (i.e., the NASICON cell is electrostatically neutral). However, each migration unit can exhibit random occupancies of Si/P in Si/P sites, and Na/vacancies in the $\mathrm{Na}(2)$ sites (panels $\mathbf{b}, \mathbf{c}$ and $\mathbf{d}$ of Figure 1). Consequently, the migration of Naions may occur through migration units that are not locally charge neutral, i.e., a given unit by itself may not be electrostatically neutral. In our work, we consider all possible 
$\mathrm{Na}(1) \leftrightarrow \mathrm{Na}$ (2) hopping events within a given migration unit, including scenarios with and without local charge neutrality.

We evaluated all the unique $\mathrm{Na}$-ion migration pathways that are possible within a migration unit of Figure 1d using the nudged elastic band method (NEB) ${ }^{35}$ together with density functional theory (DFT), and using the strongly constrained and appropriately normed (SCAN) meta-generalized gradient approximation. ${ }^{36}$ The NEB method is designed to calculate migration barriers in solid electrolytes, as highlighted by prior studies. ${ }^{2,3,37,38}$ We identified 32 unique Na-hops, given the migration unit of Figure 1d, which included barriers computed at different Si and P compositions and $\mathrm{Na} / v a c a n c y$ contents (Section S2 of the Supporting Information, SI). The calculated migration barriers at $0 \mathrm{~K}$ are defined as the difference between the highest energy state and the configuration with the lowest energy —-the initial and/or final end point. ${ }^{37}$ The accuracy of our computed barriers is validated by the excellent agreement with existing data. For example, our calculated barrier at $\mathrm{NaZr}_{2}\left(\mathrm{PO}_{4}\right)_{3}(\sim 458 \mathrm{meV}$, Table S1) agrees well with existing experimental values $(\sim 470 \mathrm{meV})^{26}$ and ab initio MD ( $472 \mathrm{meV}){ }^{32}$

Typically, migration events have an intrinsic directional dependence if the initial and final states are not equivalent, i.e., a $\mathrm{Na}(1) \rightarrow \mathrm{Na}(2)$ hop may exhibit a different migration barrier compared to the reverse hop, $\mathrm{Na}(2) \rightarrow \mathrm{Na}(1)$, due to energy differences between the end points, namely, $\mathrm{Na}(1)$ and $\mathrm{Na}(2)$. Van der Ven et al. ${ }^{39}$ introduced the kinetically resolved activation (KRA) barrier, or $\mathrm{E}_{K R A}$ (see Equation 2 in the Methods section) that removes the directional dependence of the migration barriers. Note that low values of $\mathrm{E}_{K R A}$ correspond to low values of migration barriers and vice versa. Furthermore, we trained a local cluster expansion (LCE) Hamiltonian ${ }^{40}$ on the computed $\mathrm{E}_{K R A}$ values (listed in Table $\mathbf{S} 1$ of the $\mathrm{SI}$ ), which assigns a single 
$\mathrm{E}_{K R A}$ value per migration unit and enables simulating large supercells of NASICON over long time-scales within our in-house kinetic Monte Carlo (kMC) package (Methods section and Section S3 and S4 of SI). The main advantage of the LCE over computationally expensive NEB calculations at all possible configurations, is that it enables the rapid estimation of $\mathrm{E}_{K R A}$ (and the corresponding migration barriers) at all $\mathrm{Na}(2)$, Si and $\mathrm{P}$ compositions in a given migration unit.

The average $\mathrm{E}_{K R A}$ values obtained by the LCE model are plotted in Figure 1e, with the dashed black diagonal indicating migration units that are locally charge neutral. Off-diagonal barriers are for locally charged situations and reflect multiple $\mathrm{Na}$ and Si/P configurations. For example, there are 400 possible configurations for a migration unit with $3 \mathrm{Na}$ and $3 \mathrm{Si}$, and the $\mathrm{E}_{K R A}$ of $\sim 410 \mathrm{meV}$ (Figure 1e) is obtained by averaging the barriers across all the configurations. A similar averaging procedure is used for all scenarios where multiple $\mathrm{Na} /$ vacancy and $\mathrm{Si} / \mathrm{P}$ configurations can exist within the same migration unit.

Depending on the Si/P environments, two distinct regions of high and low average $\mathrm{E}_{K R A}$ are inferred from Figure 1e. At lower Si or higher $\mathrm{P}$ content (bottom rows of Figure 1e), high average $\mathrm{E}_{K R A}(\sim 500 \mathrm{meV}$ or similar) are observed. In contrast, increasing the Si content or decreasing the P content (top rows of Figure 1e) lowers the average $\mathrm{E}_{K R A}$ (values as low as $\sim 50 \mathrm{meV}$ ). Importantly, an increase in $\mathrm{Si}$ concentration in NASICON lowers the average $\mathrm{E}_{K R A}$. The monotonic decrease in $\mathrm{E}_{K R A}$ (and migration barriers) with Si content can be attributed to lower $\mathrm{Si}^{4+}-\mathrm{Na}^{+}$electrostatic repulsion compared to $\mathrm{P}^{5+}-\mathrm{Na}^{+}$repulsion during $\mathrm{Na}$-migration.

Changing the $\mathrm{Na}$ concentration at a given Si/P content within the migration unit does not result in a monotonic increase or decrease in average $\mathrm{E}_{K R A}$. For instance, at 
4/6 Si @ Si/P site in Figure 1e, the average $\mathrm{E}_{K R A}$ is low at both $0 / 6 \mathrm{Na} @ \mathrm{Na}(2)$ site and at 6/6 $\mathrm{Na} @ \mathrm{Na}(2)$ site, with the average $\mathrm{E}_{K R A}$ reaching a maximum at 3/6 $\mathrm{Na} @$ $\mathrm{Na}(2)$ site. This non-monotonic behavior is likely due to a combination of local electrostatic repulsions and local charge imbalance within the migration unit. For example, at 6/6 Na@ $\mathrm{Na}(2)$ site and 0/6 Si @ Si/P site (bottom right corner of Figure 1e), a high $\mathrm{E}_{K R A}$ can be attributed to the higher electrostatic repulsion between the $\mathrm{Na}^{+}$ and $\mathrm{P}^{5+}$ ions. In contrast, low barriers at both 0/6 Na @ Na(2) and 6/6 $\mathrm{Na} @ \mathrm{Na}(2)$ along 4/6 Si @ Si/P are likely because of high local charge imbalance that destabilizes the initial/final $\mathrm{Na}(1)$ and $\mathrm{Na}(2)$ configurations along the pathway. Eventually, high $\mathrm{Na}$ content in the migration unit contributes to low $\mathrm{E}_{K R A}$, particularly at high Si content, as indicated by the blue squares towards the top right corner of Figure 1e. Indeed, the lowest values of $\mathrm{E}_{K R A}$ are observed at both high $\mathrm{Na}$ and high Si contents.

Combining the LCE and $\mathrm{kMC}$, we investigated the relevant Na-transport properties in NASICON, such as ionic diffusivity and conductivity. The main advantage of using a kMC framework is the access to statistically significant amounts of data over large length and time scales, as well as the ability to sample a wide variety of configurations. By comparison, a classical or ab initio MD simulation ${ }^{3,23-25}$ performs a "one shot" representative calculation of a system at a given atomic configuration and composition, over smaller length and orders of magnitude shorter time scales.

In total, more than $2,000 \mathrm{kMC}$ simulations were performed to predict the $\mathrm{Na}^{+}$ diffusivities and conductivities at selected temperatures of 373,473 and $573 \mathrm{~K}$ of 50 NASICON models (with varying Si/P configurations) at 11 distinct $\mathrm{Na}$ concentrations. Using canonical Monte Carlo simulations from our previous work, ${ }^{19} 550$ starting NASICON configurations (50 configurations $\times 11$ concentrations) were generated at high temperature $(\sim 1500 \mathrm{~K})$, which mimics the typical synthesis conditions and thermal 
treatments of $\mathrm{Na}_{1+x} \mathrm{Zr}_{2} \mathrm{Si}_{x} \mathrm{P}_{3-\mathrm{x}} \mathrm{O}_{12}$ and other NASICON-based electrodes. ${ }^{17,28,30,41}$ Using high-temperature structures as starting configurations in our kMC guarantees a random distribution of $\mathrm{PO}_{4}$ and $\mathrm{SiO}_{4}$ tetrahedra in the NASICON structures, as observed in reports. ${ }^{17,30,32,41}$ The choice of temperatures for the study of Na-transport in our work (measured at $373-573 \mathrm{~K}$ ) is largely motivated by the availability of experimental measurements to compare, but our framework can be easily extended to other temperatures as well. The comprehensive statistical analysis of this study, which addresses the role played by the $\mathrm{PO}_{4}$ and $\mathrm{SiO}_{4}$ distributions on overall Na-ion transport in $\mathrm{Na}_{1+x} \mathrm{Zr}_{2} \mathrm{Si}_{x} \mathrm{P}_{3-x} \mathrm{O}_{12}$, is essential to capture differences occurring during the sample preparation. ${ }^{19}$
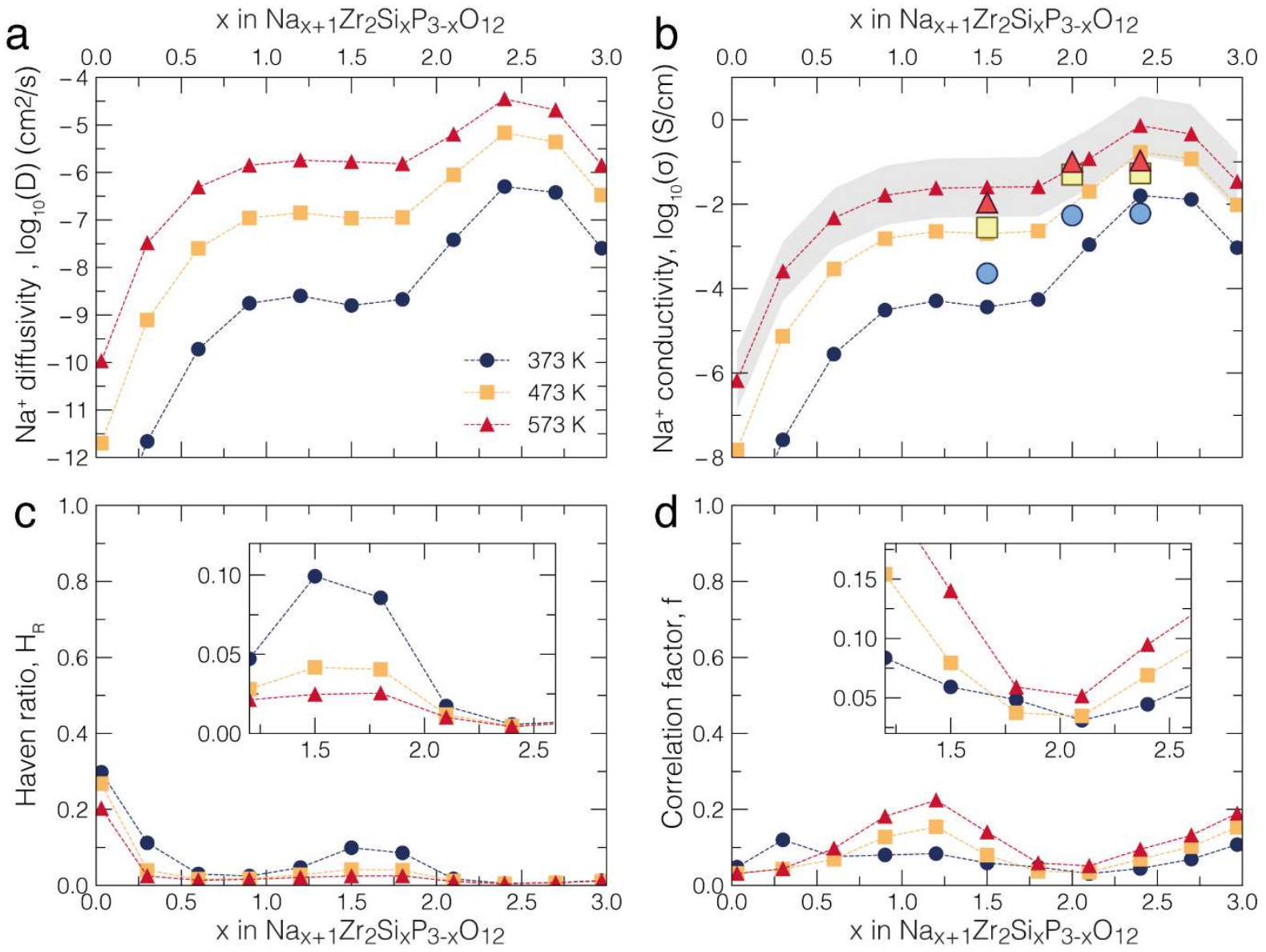
Figure 2 | Computed Na-ion transport properties of $\mathrm{Na}_{1+x} \mathrm{Zr}_{2} \mathrm{Si}_{x} \mathrm{P}_{3-\mathrm{x}} \mathrm{O}_{12}$ bulk based on kinetic Monte Carlo simulations. Calculated $\mathrm{Na}^{+}$diffusivity (a), conductivity (b), Haven's ratio (c) and averaged correlation factor (d) of $\mathrm{Na}_{1+x} \mathrm{Zr}_{2} \mathrm{Si}_{x} \mathrm{P}_{3-x} \mathrm{O}_{12}$ at several temperatures: 373 (dark blue circles), 473 (orange squares) and 573 (red triangles) K, respectively. In panel b, the computed ionic conductivities are compared with the experimental values of this work (see Figure 4 and Figure $\mathbf{S} 6$ of the $\mathrm{SI}$ ) at selected temperatures. Experimental values in $\mathbf{b}$ are depicted with larger light blue circles (373 K), yellow squares $(473 \mathrm{~K})$, and red triangles (573 $\mathrm{K})$. An exhaustive comparison with previous experimental values of ionic conductivities is shown in the Supporting Information (Figure S6). The grey band in panel b shows the interval of confidence of our predictions at $573 \mathrm{~K}$, which is lower in magnitude than the variance of $\mathrm{Na}$ ion conductivities observed experimentally (Figure S6).

Figure 2 shows the computed $\mathrm{Na}^{+}$diffusivity (D, panel a), the conductivity ( $\sigma$, panel b), Haven's ratio $\left(\mathrm{H}_{\mathrm{R}}\right.$, panel c) and averaged correlation factor $(f$, panel $\mathbf{d})$ at relevant temperatures of 373,473 , and $573 \mathrm{~K}$, from kMC simulations of $\mathrm{Na}_{1+x} \mathrm{Zr}_{2} \mathrm{Si}_{x} \mathrm{P}_{3-\mathrm{x}} \mathrm{O}_{12}$ as the $\mathrm{Na}$ content $(\mathbf{x})$ is varied. Note that the conductivity values $(\sigma)$ in Figure $\mathbf{2} \mathbf{b}$ were calculated using the Nernst-Einstein equation, as expressed in terms of diffusivity D in Equation 1.3,23,24,39,40

$$
\sigma=\frac{e^{2} C}{k_{\mathrm{B}} T} \mathrm{D}
$$

where $e$ is the elemental charge, $C$ is the concentration of $\mathrm{Na}$-ions, $k_{\mathrm{B}}$ is the Boltzmann constant and $T$ is the temperature. Importantly, in Equation 1, D is the diffusivity of the center-of-mass of Na-ions in the NASICON structure, which includes cross-correlations of the migrations of different Na-ions (see Section S4 of SI) and not the tracer diffusivity, as often used in many studies. ${ }^{23,39,40}$ 
As confirmed by Figure $\mathbf{2} \mathbf{a}$ and Figure $\mathbf{2} \mathbf{b}$, a temperature increase can significantly boost both $\mathrm{Na}^{+}$diffusivities and conductivities across the full $\mathrm{Na}$ concentration. Interestingly, $\mathrm{Na}$ diffusivity and conductivity increase for increasing $\mathrm{Na}$ (and $\mathrm{Si}$ ) concentrations up to $\mathrm{x} \sim 2.4$, beyond which there is a drop in both diffusivity and conductivity. Thus, we conclude that Na-ion transport in $\mathrm{Na}_{1+x} \mathrm{Zr}_{2} \mathrm{Si}_{x} \mathrm{P}_{3-x} \mathrm{O}_{12}$ is fastest at $\mathrm{x} \sim 2.4$, at all temperatures considered in this work, which agrees with our experimental observations presented below.

Figure $\mathbf{S 6}$ reveals a significant spread of experimentally measured ionic conductivities from different reports, ${ }^{18,27,33,42-45}$ which is indicative of the difficulties in performing accurate measurements as well as the large variability in sample preparation. Nonetheless, for $\mathrm{Na}_{3} \mathrm{Zr}_{2} \mathrm{Si}_{2} \mathrm{P}_{1} \mathrm{O}_{12}$ our measured experimental conductivity (see Figure $4 \mathbf{b}$ ) of $\sim 0.1 \mathrm{~S} \mathrm{~cm}^{-1}$ at $573 \mathrm{~K}$ is in excellent agreement with our computed value of $\sim 0.2 \mathrm{~S} \mathrm{~cm}^{-1}$. Our model also agrees with previous measurements ${ }^{18,19,30,32}$ which report a low conductivity and diffusivity in $\mathrm{Na}_{1} \mathrm{Zr}_{2} \mathrm{P}_{3} \mathrm{O}_{12}$.

Previous studies have shown that correlated ion-migration can contribute to high diffusivity and conductivity in ionic conductors. ${ }^{3,4,7,23,32,40,46,47}$ In regimes of nondilute diffusion carriers, the Haven's ratio $\left(H_{R}\right)$ of Figure 2c quantifies the degree of cross-correlation between migrating $\mathrm{Na}^{+}$ions, i.e., the extent to which individual $\mathrm{Na}^{+}$ hops contribute to the overall motion of the $\mathrm{Na}^{+}$center-of-mass (Equation $\mathbf{S 8}$ of $\mathrm{SI}$ ). $\mathrm{H}_{\mathrm{R}}$ varies between 1 (no cross-correlation or a random movement of individual $\mathrm{Na}^{+}$ ions) and 0 (fully correlated transport or non-random movement). While we observe small values of $\mathrm{H}_{\mathrm{R}}(0.01-0.2)$ throughout the $\mathrm{Na}$ concentration range in the NASICON, indicating significant cross-correlation between $\mathrm{Na}$ ions, $\mathrm{H}_{\mathrm{R}}$ at low $\mathrm{Na}$ concentrations $(x \sim 0)$ is moderately high $(\sim 0.2)$ compared to high Na concentrations $\left(H_{R} \sim 0.01\right.$ at $\left.x \sim 3\right)$. The variation in $H_{R}$ with $\mathrm{Na}$ composition $(x)$ can be partly attributed 
to the occupancy of $\mathrm{Na}$ across the $\mathrm{Na}(1)$ and $\mathrm{Na}(2)$ sites in the NASICON. For example, at $\mathrm{x} \sim 0, \mathrm{Na}^{+}$mostly resides in the $\mathrm{Na}(1)$ sites, which are separated from each other by large distances $(\sim 6.47 \AA)$, suggesting lower degrees of crosscorrelations between migrating $\mathrm{Na}^{+}$ions. At $\mathrm{x} \sim 3, \mathrm{Na}^{+}$ions populate both $\mathrm{Na}(1)$ and $\mathrm{Na}(2),{ }^{30}$ which are separated by shorter distances $(\sim 3.48 \AA)$ than $\mathrm{Na}(1)-\mathrm{Na}(1)$, possibly facilitating correlated migration of $\mathrm{Na}^{+}$ions. Interestingly, cross-correlation between $\mathrm{Na}^{+}$ions shows an increase with increasing temperature, as indicated by the drop in $\mathrm{H}_{\mathrm{R}}$ with rising temperature at all $\mathrm{x}$ (Figure 2c); this trend also coincides with increasing of $\mathrm{D}$ and $\sigma$, highlighting the positive impact of correlated motion on the overall Na-ion transport.

Another type of correlation, specifically between successive jumps of the same $\mathrm{Na}^{+}$ion, is to estimate the average correlation factor, $f$, of Figure $\mathbf{2 d}$ (see Equation $\mathbf{S 1 0}$ of the SI). $f$ measures the variation in local environments (resulting in a change of migration barriers) as experienced by individual $\mathrm{Na}^{+}$ions as they migrate through NASICON. $f$ captures the deviation away from a truly random walk of a given $\mathrm{Na}^{+}$ion within the structure, with $f=1$ indicating a true random walk and $f=0$ signifying truly non-random walk. Thus, $f$ is different from $\mathrm{H}_{\mathrm{R}}$, which describes the correlation between the motions of different $\mathrm{Na}^{+}$ions. Similarly, to our observations with $\mathrm{H}_{\mathrm{R}}$, we find that correlation effects, as measured by $f$, are quite pronounced at all Na concentrations in NASICON (Figure 2d). For example, $f$ decreases progressively from 0.2 to 0.01 as $\mathrm{x}$ varies from 1 to 2 . Notably, $f$ exhibits more significant non-monotonic behavior compared to $H_{R}$ in the range $0<x<3$.

One of the main reasons behind the high degree of correlation (as indicated by $\mathrm{H}_{\mathrm{R}}$ and $\mathrm{f}$ ) in NASICON is the high sensitivity of the $\mathrm{E}_{K R A} S$ to the local Si/P environment (Figure 1e). Indeed, one may observe large variations in the local migration units, 
which leads to significant changes in $\mathrm{E}_{K R A}$, at a given $\mathrm{Na}$ concentration. This is clearly shown in Figure S2, where the migration barrier varies between $\sim 300 \mathrm{meV}$ and $~$ $800 \mathrm{meV}$ at $\mathrm{x} \sim 2$. Every $\mathrm{Na}^{+}$migration event leads to a dynamic change in local environment by creating new vacancies and eliminating existing ones, which can have sizeable effects on the migration barriers (and hence $\mathrm{E}_{K R A}$ ), eventually resulting in highly correlated motion.
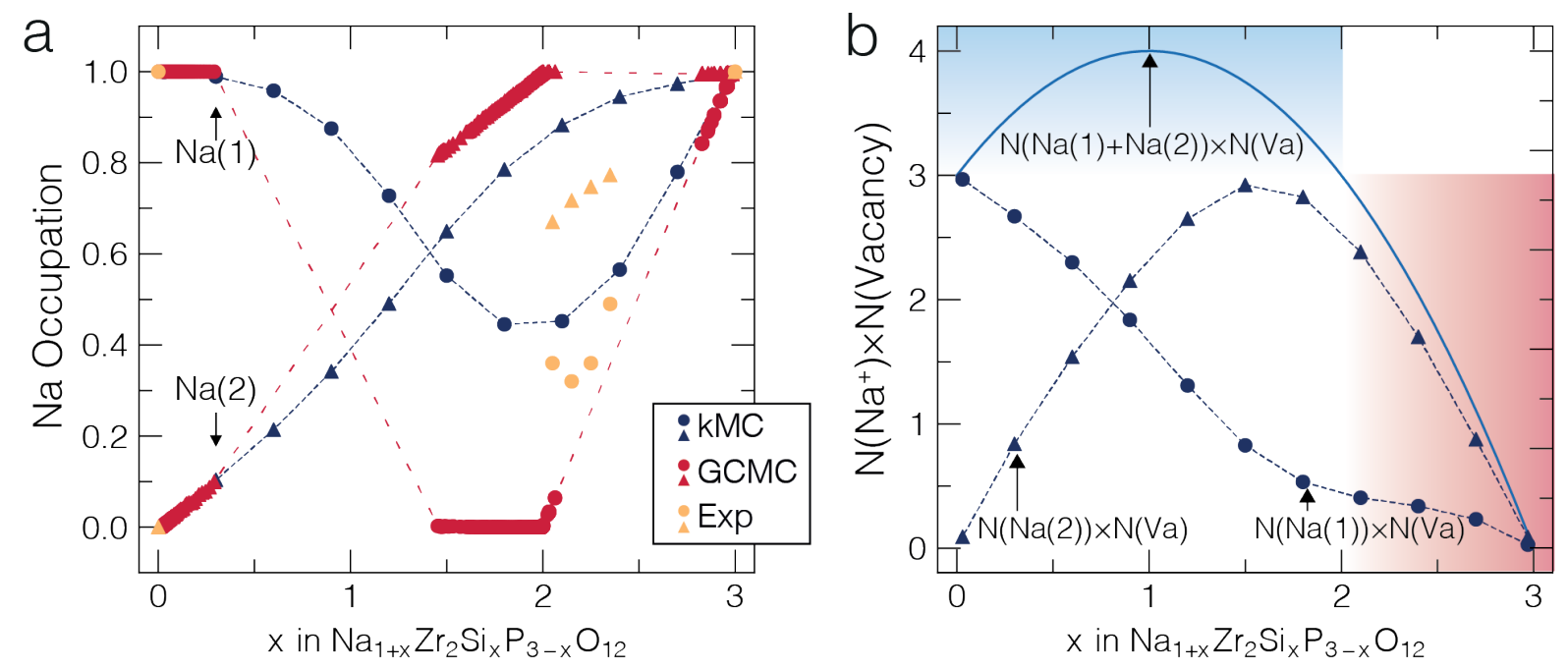

Figure 3 | Sodium occupancies and concentrations as a function of $\mathrm{Na}$ content. Panel a shows the averaged $\mathrm{Na}$ site occupancy at $\mathrm{Na}(1)$ site (blue circles) and $\mathrm{Na}(2)$ site (blue triangles) from kMC simulations at $443 \mathrm{~K}$, and compared with previous Grand Canonical Monte Carlo simulations ${ }^{19}$ (red circles and triangles) at the same temperature, and existing experimental data ${ }^{30}$ (in orange circle and triangles). Dashed lines are used as guide for the eye. Panel b shows $N\left(\mathrm{Na}^{+}\right) \times N$ (Vacancy) (solid blue curve, per f.u.) at $443 \mathrm{~K}$ from $\mathrm{kMC}$ simulations. The contributions to $N\left(\mathrm{Na}^{+}\right) \times N$ (Vacancy) from individual sodium sites, $\mathrm{Na}(1)$ and $\mathrm{Na}(2)$, are shown as blue dashed lines. In panel $\mathbf{b}$, the shaded regions mark areas where $\mathrm{Na}^{+}$-ion conductivity is highly (red) or slightly (blue) impacted by the charge carrier concentration.

It is worth analyzing how the distribution of $\mathrm{Na}$-ions, across the $\mathrm{Na}(1)$ and $\mathrm{Na}(2)$ sites controls the $\mathrm{Na}$ diffusivity (and conductivity) of NASICON. Figure 3a shows the 
averaged $\mathrm{Na}$ occupancy of the $\mathrm{Na}(1)$ and $\mathrm{Na}(2)$ sites, as extracted from our $\mathrm{kMC}$ simulations. We compare these values with single-crystal X-ray diffraction experiments by Boilot et al. ${ }^{30}$ at specific compositions, and our previous grandcanonical Monte Carlo simulations, ${ }^{19}$ which do not account for the dynamics of the $\mathrm{Na}^{+}$ ions.

In NASICONs, ${ }^{18,48} \mathrm{Na}$-transport can only occur if multiple exchanges between $\mathrm{Na}(2) \leftrightarrow \mathrm{Na}(1)$ sites occur. ${ }^{18,30,31}$ This implies that both $\mathrm{Na}(1)$ and $\mathrm{Na}(2)$ must be occupied to some degree $\mathrm{e}^{18,30,31}$ for facile transport. The Na site occupancies derived from our kMC data which includes possible Na-migration events, at $443 \mathrm{~K}\left(170{ }^{\circ} \mathrm{C}\right.$, blue shapes in Figure 3a) show that both $\mathrm{Na}(1)$ and $\mathrm{Na}(2)$ are partially occupied at compositions $1<x<3$. The $\mathrm{kMC}$ results are in qualitative agreement with $\mathrm{X}$-ray measurements at $443 \mathrm{~K}$ of Ref. ${ }^{30}$ (orange shapes in Figure 3a). In contrast, occupations generated by the grand-canonical Monte Carlo model (red filled shapes in Figure 3a) indicate the equilibrium $\mathrm{Na}$ occupancies, which are distinctly different from the kMC simulations (and experiments) that include the impact of $\mathrm{Na}$ movement.

Importantly, both our kMC and grand-canonical Monte Carlo simulations indicate that at $\mathrm{Na}_{1} \mathrm{Zr}_{2} \mathrm{P}_{3} \mathrm{O}_{12}, \mathrm{Na}^{+}$ions will be almost exclusively located at $\mathrm{Na}(1)$, even after including $\mathrm{Na}^{+}$dynamics at $443 \mathrm{~K}$ (Figure 3a). ${ }^{32}$ In $\mathrm{Na}_{1} \mathrm{Zr}_{2} \mathrm{P}_{3} \mathrm{O}_{12}$, the $\mathrm{Na}$ (2) sites are empty because they are not thermodynamically stable at this composition. ${ }^{32,41}$ Thus, the lack of $\mathrm{Na}$ atoms present in $\mathrm{Na}(2)$ sites that can act as diffusion carriers, contributes significantly to the low $\mathrm{D}($ and $\sigma)$ observed at low $\mathrm{Na}$ content $(\mathrm{x} \sim 0$, Figure 2), in addition to the high $\mathrm{E}_{K R A}$ observed (i.e., at low values of $\mathrm{Na@} \mathrm{Na}(2)$ and $\mathrm{Si} @$ $\mathrm{Si} / \mathrm{P}$ in Figure 1e).

By contrast, at high $\mathrm{Na}$ contents $\left(x \sim 3, \mathrm{Na}_{4} \mathrm{Zr}_{2} \mathrm{Si}_{3} \mathrm{O}_{12}\right), \mathrm{Na}^{+}$diffusion is mostly limited by a lack of $\mathrm{Na}$ vacancies (either on $\mathrm{Na}(1)$ or $\mathrm{Na}(2)$ sites), which contributes to 
the moderately low computed $\mathrm{D}$ and $\sigma$. Note that the computed $\mathrm{E}_{K R A}$ barriers achieve their lowest values corresponding to high $\mathrm{Na}$ and $\mathrm{Si}$ content (Figure 1e), which is similar to the local migration units that will be observed at $x \sim 3$, and should, in principle, contribute to increase D and $\sigma$. However, the sharp decrease in the number of available vacancies prevails over the decrease in $\mathrm{E}_{K R A}$, eventually lowering $\mathrm{D}$ and $\sigma$. While we only consider vacancy-based migration mechanisms in our work, a recent study has also explored interstitial-based migration mechanisms in various solid electrolytes. ${ }^{49}$ Given the robust agreement between our predictions and measurements, we believe that an interstitial-based mechanism is not active within NASICON structures.

Figure $3 b$ further quantifies the extent of diffusion carrier availability within the NASICON structure. For example, the solid blue curve of Figure $\mathbf{3 b}$ shows the product of the number of $\mathrm{Na}$ ions and vacancies in the structure $\left[N\left(\mathrm{Na}^{+}\right) \times N(\right.$ Vacancy $\left.)\right]$, which is a proxy for the availability of diffusion carriers in the structure, as a function of $\mathrm{Na}$ content. Figure $\mathbf{3 b}$ also splits the concentration of $\mathrm{Na}$ ions, $N\left(\mathrm{Na}^{+}\right)$, into site-specific quantities, $N(\mathrm{Na}(1))$ and $N(\mathrm{Na}(2))$, as indicated by the dashed blue curves.

In the blue-shaded region of Figure $3 \mathbf{b}$ in the range $0<x<2$, $N\left(\mathrm{Na}^{+}\right) \times N$ (Vacancy) is extended, signifying high availability of diffusion carriers, but the barriers for $\mathrm{Na}$ motion are large as well (bottom half of Figure 1e). In striking contrast, for $\mathrm{x}>2, N\left(\mathrm{Na}^{+}\right) \times N($ Vacancy) decreases sharply, along with a decrease in $E_{K R A}$ as well (top half of Figure 1e), signifying an increase in D and $\sigma$ up to $\mathrm{x} \sim 2.4$ followed by an eventual decline of both quantities as $x \rightarrow 3$. In Figure $3 a$, at $x=3$, both $\mathrm{Na}(1)$ and $\mathrm{Na}(2)$ sites are filled and no free charge carriers are available. 
Experimentally and theoretically, ${ }^{17-19,30}$ at $x \sim 2.4$ both $\mathrm{Na}(1)$ sites and $\mathrm{Na}(2)$ sites are expected to be occupied to some degree and the $\mathrm{Na}^{+}$has enough vacancies to migrate. Furthermore, we expect the overall migration barriers to be low at $x \sim 2.4$ compared to $\mathrm{x}<2$, as quantified by trends in $\mathrm{E}_{K R A}$ in Figure 1e. Therefore, $\mathrm{Na}_{3.4} \mathrm{Zr}_{2} \mathrm{Si}_{2.4} \mathrm{P}_{0.6} \mathrm{O}_{12}$ strikes the optimal combination of density of diffusion carriers (i.e., availability of $\mathrm{Na}$ ions and vacancies in both $\mathrm{Na}(1)$ and $\mathrm{Na}(2)$ sites), and low migration barriers to achieve the fastest Na-transport in the NASICON electrolyte.

We have synthesized different compositions of the NASICON, namely, $\mathrm{Na}_{2.5} \mathrm{Zr}_{2} \mathrm{Si}_{1.5} \mathrm{P}_{1.5} \mathrm{O}_{12}, \mathrm{Na}_{3} \mathrm{Zr}_{2} \mathrm{Si}_{2} \mathrm{P}_{1} \mathrm{O}_{12}$, and $\mathrm{Na}_{3.4} \mathrm{Zr}_{2} \mathrm{Si}_{2.4} \mathrm{P}_{0.6} \mathrm{O}_{12}$ and tested their Na-ion transport characteristics. Figure $\mathbf{4 a}$ shows the powder $\mathrm{X}$-ray diffractions (PXRD) measured at room temperature, with the PXRD profiles matching the rhombohedral $(R \overline{3} c) \quad \mathrm{Na}_{2.5} \mathrm{Zr}_{2} \mathrm{Si}_{1.5} \mathrm{P}_{1.5} \mathrm{O}_{12}$, the monoclinic $(C 2 / c) \quad \mathrm{Na}_{3} \mathrm{Zr}_{2} \mathrm{Si}_{2} \mathrm{P}_{1} \mathrm{O}_{12}$, and $C 2 / c-$ $\mathrm{Na}_{3.4} \mathrm{Zr}_{2} \mathrm{Si}_{2.4} \mathrm{P}_{0.6} \mathrm{O}_{12}$ structures, respectively. Information about the synthesis of these NASICON compositions are discussed in the Methods section. 

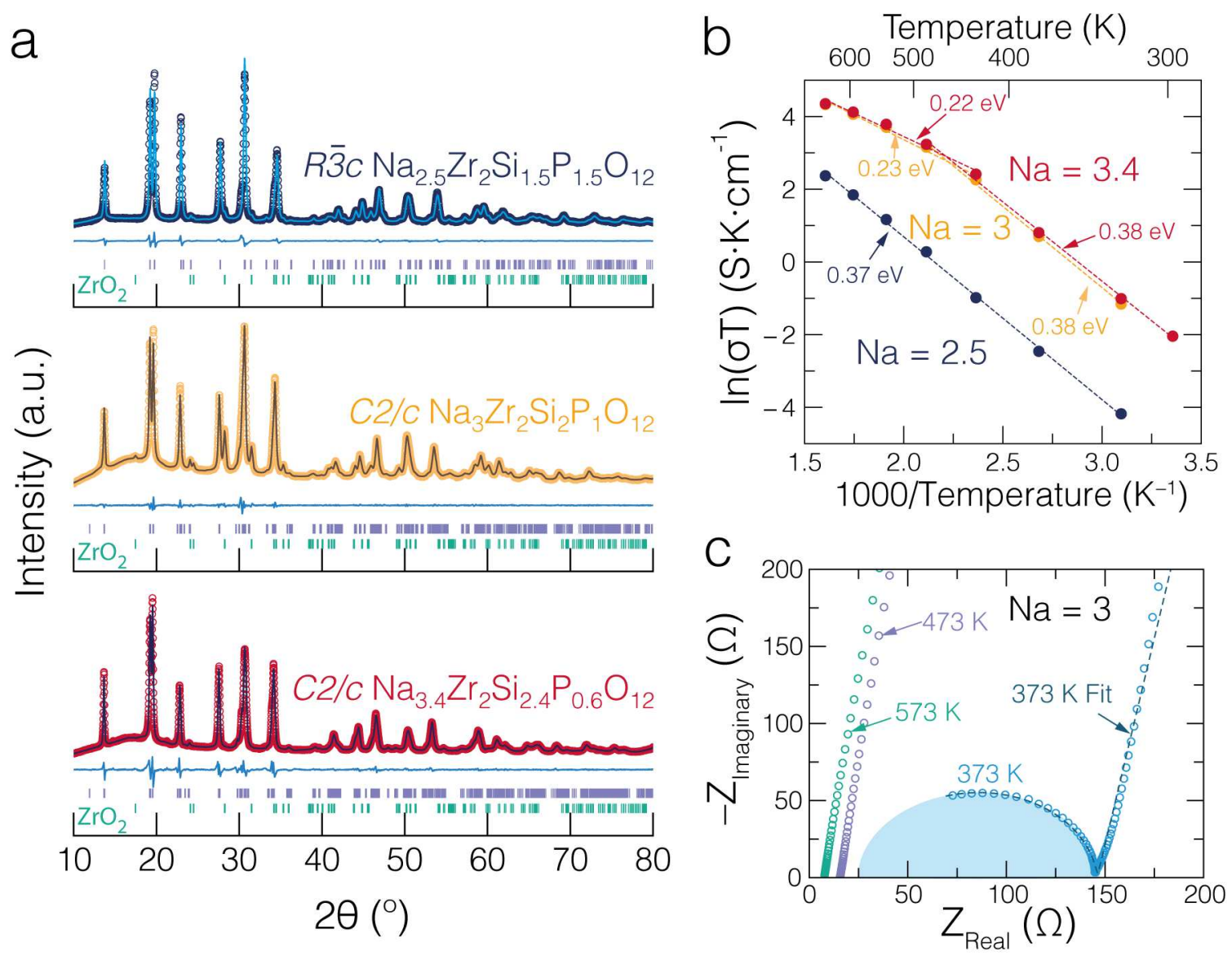

Figure 4 | Room temperature powder X-ray diffraction of selected NASICON compounds and their ionic conductivities measured using the pellets formed by these powders. In panel a, X-Ray diffraction pattern (dark blue, orange, and red circles), and Le Bail fitting (solid lines in cyan, dark brown and dark red) for synthesized $\mathrm{Na}_{1+x} \mathrm{Zr}_{2} \mathrm{Si}_{x} \mathrm{P}_{3-\mathrm{x}} \mathrm{O}_{12}(\mathrm{x}=1.5,2.0$, and 2.4). b Arrhenius plot from $A C$ impedance measurements of synthesized samples $(x=1.5$ in dark blue, $x=2.0$ in orange, $x=2.4$ in red). $c$ Representative Nyquist plot for $\mathrm{Na}_{3} \mathrm{Zr}_{2} \mathrm{Si}_{2} \mathrm{P}_{1} \mathrm{O}_{12}$ at variable measured at 373 (blue), 473 (purple) and $573 \mathrm{~K}$ (green). Other Nyquist plots are Figure S9 in the SI.

The refined lattice parameters of $\mathrm{Na}_{2.5} \mathrm{Zr}_{2} \mathrm{Si}_{1.5} \mathrm{P}_{1.5} \mathrm{O}_{12}, \quad \mathrm{Na}_{3} \mathrm{Zr}_{2} \mathrm{Si}_{2} \mathrm{P}_{1} \mathrm{O}_{12}$ and $\mathrm{Na} 3.4 \mathrm{Zr}_{2} \mathrm{Si}_{2.4} \mathrm{P}_{0.6} \mathrm{O}_{12}$ are listed in Table 1 and are in agreement with existing reports. ${ }^{17,50}$ The phase purity of these compounds enables us to characterize their variable temperature $\mathrm{Na}$ ionic conductivities, as reported in the Arrhenius plots of Figure $\mathbf{4 b}$. 
Impedance spectra at variable temperatures and their fitting details are also provided in Figure S9 and related text in the SI.

Table 1 | Lattice parameters of selected NASICON samples obtained from room temperature PXRD. Lattice constants, angles and volumes are in $\AA$, o, and $\AA^{3}$, respectively. $Z$ is the number of formula units.

\begin{tabular}{lccc}
\hline & $\mathrm{Na}_{2.5} \mathrm{Zr}_{2} \mathrm{Si}_{1.5} \mathrm{P}_{1.5} \mathrm{O}_{12}$ & $\mathrm{Na}_{3} \mathrm{Zr}_{2} \mathrm{Si}_{2} \mathrm{P}_{1} \mathrm{O}_{12}$ & $\mathrm{Na}_{3.4} \mathrm{Zr}_{2} \mathrm{Si}_{2.4} \mathrm{P}_{0.6} \mathrm{O}_{12}$ \\
\hline Space group & $R \overline{3} c$ & $C 2 / c$ & $C 2 / c$ \\
$a$ & $8.9864(13)$ & $15.6565(16)$ & $15.7571(15)$ \\
$b$ & $8.9864(13)$ & $9.0634(7)$ & $9.0835(7)$ \\
$c$ & $22.960(5)$ & $9.2216(15)$ & $9.2549(8)$ \\
$\beta$ & - & $124.255(8)$ & $124.963(5)$ \\
Volume & $1605.7(5)$ & $1081.6(2)$ & $1085.58(16)$ \\
$Z$ & 6 & 4 & 4 \\
Volume/Z & 267.6 & 270.4 & 271.40 \\
\hline
\end{tabular}

The ionic conductivities of the synthesized $\mathrm{Na}_{1+x} \mathrm{Zr}_{2} \mathrm{Si}_{x} \mathrm{P}_{3-\mathrm{x}} \mathrm{O}_{12}$ phases at variable temperature were fitted with appropriate equivalent circuits (see Methods section). The extracted activation energies for all three NASICON compositions were obtained from the Arrhenius plots $(\operatorname{In}(\sigma \mathrm{T})$ vs. $1000 / \mathrm{T})$ of Figure $\mathbf{4 b}$. For the composition $x=1.5$, the extracted activation energy is $\sim 0.37 \mathrm{eV}$, and no phase transition is observed due to the stability of the rhombohedral phase at room and higher temperatures. Both compositions at $x=2.0$ and $x=2.4$ show two linear domains with different activation energies displayed in Figure $\mathbf{4 b}$. Thus, the Arrhenius plots of Figure $\mathbf{4 b}$ reproduce the documented monoclinic-to-rhombohedral phase transition upon heating for the compositions $\mathrm{Na}_{3} \mathrm{Zr}_{2} \mathrm{Si}_{2} \mathrm{P}_{1} \mathrm{O}_{12}$, and $\mathrm{Na}_{3.4} \mathrm{Zr}_{2} \mathrm{Si}_{2.4} \mathrm{P}_{0.6} \mathrm{O}_{12}$ at $\sim 433 \pm 15 \mathrm{~K} .{ }^{51-53}$ Heating and cooling responses of ionic conductivity vs. temperature for the three compositions are discussed in Figure $\mathbf{S 1 0}$ of the SI. The activation energies for $\mathrm{x}=2.0$ are $0.38 \mathrm{eV}$ (below the phase transition $\sim 433 \mathrm{~K}$ ) and $0.22 \mathrm{eV}$ (above $\sim 433 \mathrm{~K}$ ), which are in good agreement with previous works. ${ }^{41,54-60} \mathrm{Na}_{3.4} \mathrm{Zr}_{2} \mathrm{Si}_{2.4} \mathrm{P}_{0.6} \mathrm{O}_{12}$ shows similar activation 
energies, with values of $0.38 \mathrm{eV}$ (below $\sim 433 \mathrm{~K}$ ) and $0.22 \mathrm{eV}($ above $\sim 433 \mathrm{~K}$ ) at $x=2.4$, in agreement with Ref. ${ }^{54}$.

An example of a Nyquist plot used to extract the total ionic conductivity from the sintered pellets of the NASICON compositions at variable temperatures $(373 \mathrm{~K}$, $473 \mathrm{~K}$, and $573 \mathrm{~K}$ ) is given in Figure 4c. The composition with $\mathrm{x}=1.5$ has the lowest ionic conductivity for all temperatures compared to structures with $x=2.0$ and 2.4 . Note, low-temperature impedance measurements of the monoclinic $\mathrm{Na}_{3.4} \mathrm{Zr}_{2} \mathrm{Si}_{2.4} \mathrm{P}_{0.6} \mathrm{O}_{12}$ phase do indicate high Na-conductivity. ${ }^{58}$ The ionic conductivity of $x=2.0$ showed that the measured values of this work are within the range of reported values. ${ }^{41,61,43,44,18,45,27}$

\section{Discussion}

Experimentally, ionic diffusivity can be measured by a number of techniques, such as solid-state nuclear magnetic resonance, quasi elastic neutron scattering and secondary-ion mass spectroscopy, ${ }^{20,62}$ while $A C$ impedance spectroscopy is the method of choice for determining ionic conductivity in solid electrolytes. ${ }^{63}$ Indeed, we have used AC impedance spectroscopy in this study. Although classical and ab initio molecular dynamics simulations have proved invaluable in the prediction of ionic conductivities in solid electrolytes,,$^{2,3,7,20,22,24,40,46,64-67}$ we have demonstrated that firstprinciples-based kMC can access significantly longer time scales in the millisecond range and larger length scales (a total of 21,504 atom supercells in the present work), enabling us to approach experimental time and space resolutions and establish a robust link between measurements and theory. To the best of our knowledge, this is 
the first study to use a LCE+kMC approach, bearing the accuracy of DFT calculations, to probe the ion-dynamics in solid electrolytes.

Our kMC simulations provide the hopping frequencies of $\mathrm{Na}^{+}$migration, of different $\mathrm{Na}$ concentrations and temperatures, which can be efficiently evaluated and mapped in large supercell models. The hopping frequency is defined in Equation S4 in the SI and includes the attempt frequency and the migration barrier. From our kMC data, we plot heatmaps indicating the spatial migration of Na-ions in Figure 5, along with the frequency associated with each $\mathrm{Na}$ migration event. Figure $\mathbf{5}$ shows the hopping frequency of three representative NASICON compositions, i.e., $x=0.3,2.4$, and 2.97, capturing Na-ion transport in low, intermediate, and high sodium concentrations. Each panel in Figure 5 contains 1,024 migration units (Figure 1e), where each migration unit is represented by a distinct colored hexagonal prism. In Figure 5, the migration units with high hopping frequencies, shown by red prisms, imply that Na-ions have a high probability of migrating beyond the migration unit, thus contributing actively to macroscopic diffusion (the inference is vice versa for blue/purple prisms corresponding to low hopping frequencies). Expectedly, as discussed in Figure 2, $x=2.4$ shows significantly higher hopping frequency compared to compositions $x=0.3$, and 2.97. 

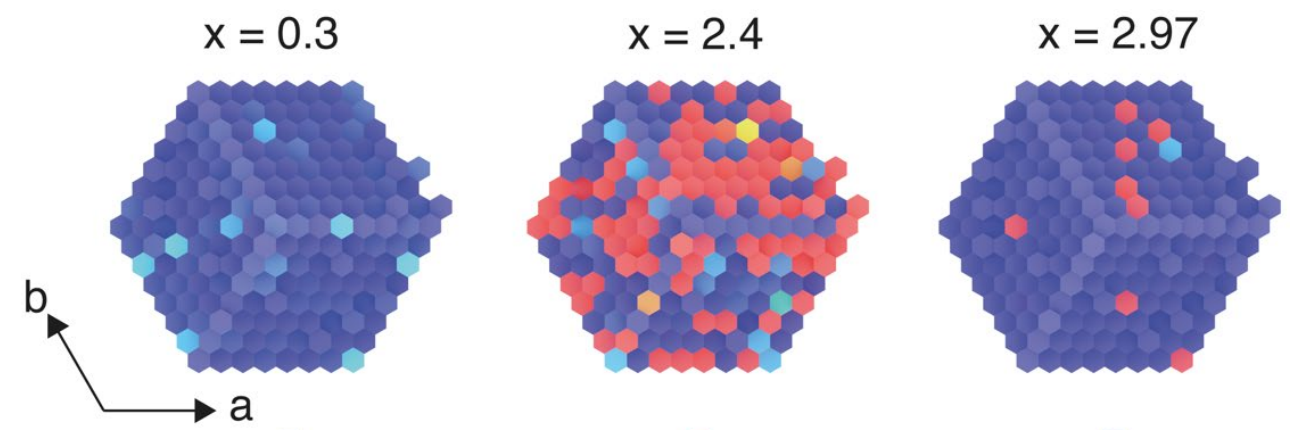

View from

[001]
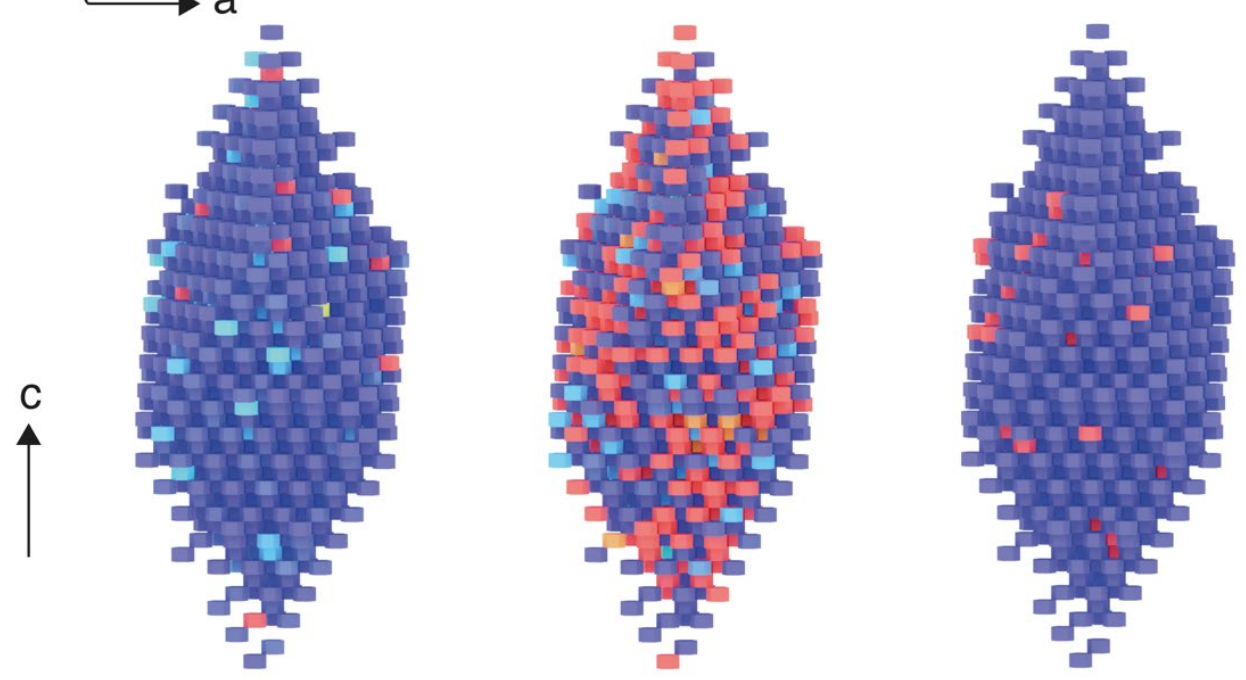

$5 \times 10^{7} \mathrm{~Hz}$
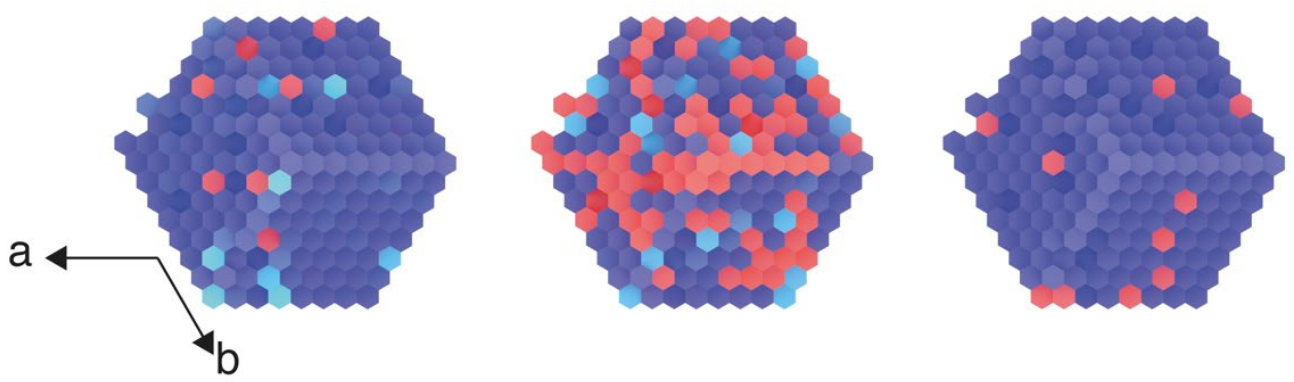

View from

$[00 \overline{1}]$

Figure 5 | Sodium hopping frequencies in NASICON materials. Heatmap representation of the frequency (in $\mathrm{Hz}$ ) of $\mathrm{Na}$-ion migration from selected $\mathrm{kMC}$ simulation supercells $(8 \times 8 \times 8$ of the primitive cell, including 1,024 migration units) at Na contents of $x=0.3,2.4$ and 2.97. The temperature in all panels is $573 \mathrm{~K}$. Each colored hexagonal prism represents a migration unit, as exemplified in Figure 1d. The hopping frequency of each migration unit is taken by averaging the probability of the six possible migrations of $\mathrm{Na}^{+}$between the central $\mathrm{Na}(1)$ site and the six $\mathrm{Na}(2)$ sites in each unit. The top and bottom panels show views along the $c$-axis from above and below the supercells.

The direct visualization of the hopping frequency of $\mathrm{Na}^{+}$migration is insightful for unravelling the respective effects played by $\mathrm{PO}_{4}$ and $\mathrm{SiO}_{4}$ moieties on the overall $\mathrm{Na}^{+}$ transport. In Figure 5, at low Na concentrations, e.g., $x=0.3$, most migration units 
appear purple (low frequency) signifying low diffusivity/conductivity, whereas these blue regions turn progressively to yellow and eventually red for increasing values of $\mathrm{x}$. At $x \sim 2$, most Na-ions are actively engaged in ion transport as most migration units are red (Figure 5), highlighting facile ionic transport, consistent with the highest values of observed $D$ and $\sigma$ at $x \sim 2.4$ (Figure 2). As $x$ approaches $3(x \sim 2.97$ shown in Figure 5), the color of the migration units eventually become purple, coinciding with the drop in $\mathrm{D} / \sigma$ at high Na-contents (Figure 2) due to the low availability of $\mathrm{Na}$ vacancies. This informative analysis can be extended to other topical solid electrolytes with mixed polyanion sulfides, such as, $\mathrm{GeS}_{4}, \mathrm{PS}_{4}, \mathrm{SiS}_{4}$, etc. ${ }^{8,9,12-14}$

The underlying structural models to generate the data in Figure $\mathbf{5}$ are based on disordered NASICON structures, where at a given $\mathrm{Na}$ concertation the $\mathrm{SiO}_{4}$ and $\mathrm{PO}_{4}$ units are randomly distributed. This is also the case of the most researched sulfide electrolytes for Li-ion solid-state batteries with various degree of mixing of $\mathrm{GeS}_{4}, \mathrm{SiS}_{4}$, $\mathrm{SiS}_{4}$ and $\mathrm{SnS}_{4}$ moieties..$^{9,11-14}$ Thus, these NASICON structures truly mimic the experimental synthesis conditions $\left(\sim 1200^{\circ} \mathrm{C}\right.$ for solid-state synthesis $\left.{ }^{18,33}\right)$ and/or heat treatments (e.g., low-temperature sol-gel synthesis ${ }^{27,68}$ followed by sintering at $\sim 1200$ ${ }^{\circ} \mathrm{C}$ for densification ${ }^{18,33,68}$ ), which quench the disorder of the phosphate and silicate units accessed at high temperatures. Previously we have shown that under equilibrium conditions NASICON should phase separate into P-rich and Si-rich domains, particularly across $\mathrm{Na}$ concentrations from $\mathrm{x}=0$ to $2 .{ }^{19}$ It is also important to understand the impact of phase separation (or lack thereof) on Na-diffusivity and conductivity.

We have extended our $\mathrm{kMC}$ model to structures produced in regimes of complete phase separation in Figure S7 of the SI. Notably, the computed ionic conductivity and other related quantities predicted in regimes of phase separation look 
similar to those reported in Figure 2, with the exception of a dip in D and $\sigma$ around $x$ $\sim 1.8-2$ compared to the scenario of fully disordered system (non-phase separated). However, this dip in ion transport properties approximately accounts for one order of magnitude, well within the error of the available experiments and our calculations, thus making it challenging to detect the signature of phase separation via diffusivity/conductivity measurements or calculations. Our calculations suggest that $\mathrm{Na}$ diffusivity and conductivity cannot be used to identify the underlying phases within the NASICON electrolyte. We believe this conclusion may also be valid for other solid electrolytes and electrodes of interest, particularly those adopting the NASICON structure, which can also thermodynamically favor phase separation. ${ }^{69,70}$ Notably, heatmaps produced in structures with phase separation (Figure S8) do clearly depict the presence of phase boundaries (differentiating Si-rich and P-rich domains), indicating that robust structural characterizations are still the best way of detecting phase separation.

Our computed barriers and $\mathrm{kMC}$ simulations suggest that higher $\mathrm{Na}^{+}$ conductivity in NASICON can simply be achieved by increasing the $\mathrm{SiO}_{4}$ to $\mathrm{PO}_{4}$ ratio. There are two reasons for this: (i) higher $\mathrm{Si}^{4+}$ content decreases that of $\mathrm{P}^{5+}$ cations in the system, thereby reducing the electrostatic repulsion between the $\mathrm{Na}^{+}$and $\mathrm{P}^{5+}$ cations during $\mathrm{Na}$ migration, and (ii) due to the longer $\mathrm{Si}-\mathrm{O}$ bonds in $\mathrm{SiO}_{4}$ compared to the $\mathrm{P}-\mathrm{O}$ bonds in $\mathrm{PO}_{4}$, Si-rich migration units will be larger, facilitating migration of large ions, such as $\mathrm{Na}^{+}$. Thus, tuning the $\mathrm{Si}$ concentration (or, equivalently, increasing the number of $4+$ instead of $5+$ cations within the polyanion groups) in the NASICON structure (via aliovalent doping, for example), clearly provides a new way for optimizing ionic transport in this class of ionic conductors. 
Indeed, the last $\sim 40$ years of research on NASICON materials has investigated aliovalent doping as a way to improve the Na-ion conductivity of this material. An increase of $\mathrm{Na}$ ions is typically achieved by subvalent doping of the $\mathrm{Zr}^{4+}$ with trivalent $\mathrm{Al}^{3+}, \mathrm{Cr}^{3+}, \mathrm{Dy}^{3+}, \mathrm{Er}^{3+}, \mathrm{Fe}^{3+}, \mathrm{Gd}^{3+}, \mathrm{In}^{3+}, \mathrm{Sc}^{3+}, \mathrm{Tb}^{3+}, \mathrm{Y}^{3+}$ and $\mathrm{Yb}^{3+}$, and/or divalent $\mathrm{Co}^{2+}$ $\mathrm{Mg}^{2+}, \mathrm{Ni}^{2+}$ and $\mathrm{Zn}^{2+}$ species. ${ }^{32,26,28,71-73,41}$ Combining a high Si content in the structure with trivalent doping on $\mathrm{Zr}^{4+}$ can potentially improve $\mathrm{Na}$ transport at high $\mathrm{Na}$ concentrations in NASICONs $(x \rightarrow 3)$. Alternatively, supervalent doping on the $\mathrm{Zr}^{4+}$ site with $\mathrm{V}^{5+}, \mathrm{Bi}^{5+}, \mathrm{Sb}^{5+}, \mathrm{Nb}^{5+}$ and $\mathrm{Ta}^{5+}$ cations is used to increase the number of $\mathrm{Na}$ vacancies, and also to reduce (by $\sim 30 \mathrm{~K}$ ) the temperature of the monoclinic-torhombohedral phase transition. ${ }^{74}$ Supervalent doping is also a viable strategy for increasing the Si content in the NASICON structure while preserving the stoichiometric ratio of $\mathrm{Na-ions}$ and vacancies. Specifically, the ionic radii of $\mathrm{Sb}^{5+}(\sim 0.60 \AA), \mathrm{Nb}^{5+}(\sim$ $0.64 \AA)$ and $\mathrm{Ta}^{5+}(\sim 0.64 \AA)$ in octahedral environments appear compatible with that of $\mathrm{Zr}^{4+}(\sim 0.72 \AA) .{ }^{75}$ The higher stability of the $5+$ oxidation state of the three candidates represents the most viable choice for incorporating more Si into the NASICON structure. Furthermore, it has been shown that isovalent doping of $\mathrm{Ge}^{4+}$ on $\mathrm{Si}^{4+}$ can also increase the size of the migration unit, ${ }^{76}$ potentially facilitating Na-diffusion. 


\section{Conclusions}

We have used a combination of state-of-the-art computational tools to explain the influence of polyanion mixing, composition and temperature on ionic transport in $\mathrm{Na}_{1+\times} \mathrm{Zr}_{2} \mathrm{Si}_{\times} \mathrm{P}_{3-\times} \mathrm{O}_{12}$, as an example ionic conductor. This was achieved by using a combination of density functional theory-based nudged elastic band calculations, a local cluster expansion Hamiltonian, and kinetic Monte Carlo simulations over millisecond timescales and nanometer length scales. Our study has demonstrated that low migration barriers for $\mathrm{Na}^{+}$-ions can be achieved by having local environments that are rich in $\mathrm{Si}$ and $\mathrm{Na}$, which can be attributed to the lower electrostatic repulsion between $\mathrm{Si}^{4+}$ and $\mathrm{Na}^{+}$(vs. $\mathrm{P}^{5+}$ and $\mathrm{Na}^{+}$) during $\mathrm{Na}$ migration. A further increase of $\mathrm{Si}$ content in $\mathrm{Na}_{1+\times} \mathrm{Zr}_{2} \mathrm{Si}_{\times} \mathrm{P}_{3-\times} \mathrm{O}_{12}$ can be achieved by doping $\mathrm{Zr}$ with stable $5+$ cations, such as $\mathrm{Ta}, \mathrm{Nb}, \mathrm{Sb}$, while maintaining an optimal $\mathrm{Na}$ composition. Importantly, we discovered a complex interplay between migration barriers and diffusion carrier availability in determining the overall ionic diffusivity/conductivity. For example, at low Na concentrations $(0<x<2)$, high migration barriers dominate, resulting in a gradual increase in diffusivity/conductivity with increasing $x$. At high Na concentrations ( $x>$ 2.5), the lack of diffusion carriers dominates (despite low migration barriers), resulting in a drop in diffusivity/conductivity. Thus, we observe that a Na composition of $x \sim 2.4$ is optimal in terms of combining enough diffusion carriers with low migration barriers, resulting in the highest diffusivity/conductivity. Through synthesis and characterization of the $\mathrm{Na}_{3.4} \mathrm{Zr}_{2} \mathrm{Si}_{2.4} \mathrm{P}_{0.6} \mathrm{O}_{12}$, we have confirmed its high Na-conductivity, as predicted by our simulations. Using $\mathrm{Na}_{1+\times} \mathrm{Zr}_{2} \mathrm{Si}_{\times} \mathrm{P}_{3-\times} \mathrm{O}_{12}$ as a model system, we demonstrated the importance of sampling statistically vast composition, length, and time scales to capture the highly correlated ionic motion that can be observed in mixed polyanion

systems. Our findings are significant for the optimization of mixed polyanion solid 
electrolytes, such as sulfide-based systems which can achieve regimes of super-ionic conductivity.

\section{Methods}

\section{Sodium Migration Barriers from Density Functional Theory}

Na migration barriers were calculated using the nudged elastic band (NEB) method ${ }^{35}$ through density functional theory (DFT) simulations as implemented in the Vienna ab initio simulation package (VASP) $\cdot{ }^{77,78}$ All the calculation parameters used in the DFT simulations can be found in Section $\mathbf{S 2}$ of the SI. The NEB barriers were modeled at 3 representative $\mathrm{Na}$ concentrations, at $\mathrm{x}=0,2$, and 3 as in $\mathrm{Na}_{1+x} \mathrm{Zr}_{2} \mathrm{Si}_{x} \mathrm{P}_{3-\mathrm{x}} \mathrm{O}_{12}$. This selection is motivated by our previous knowledge on the compositional phase diagram of $\mathrm{Na}_{1+x} \mathrm{Zr}_{2} \mathrm{Si}_{x} \mathrm{P}_{3-\mathrm{x}} \mathrm{O}_{12},{ }^{19}$ where NASICON exhibits three distinct ground states at $0 \mathrm{~K}$.

Special care is required for the NEB barrier calculations of $\mathrm{NaZr}_{2}\left(\mathrm{PO}_{4}\right)_{3}(x=0)$ which follows a pathway $\mathrm{Na}(1) \rightarrow \mathrm{Na}(2) \rightarrow \mathrm{Na}(1)$. In $\mathrm{NaZr}_{2}\left(\mathrm{PO}_{4}\right)_{3}$ all the $\mathrm{Na}(1)$ sites are occupied and $\mathrm{Na}$ migration is only possible if vacancies in $\mathrm{Na}(1)$ are introduced. For this specific case the energy required for $\mathrm{Na}^{+}$migration should also include the formation energy of Na vacancy, which we computed using the method of Ref. ${ }^{79}$. We found that the $\mathrm{Na}$ vacancy formation energy in $\mathrm{NaZr}_{2}\left(\mathrm{PO}_{4}\right)_{3}$ is $\sim 474 \mathrm{meV}$, which we added in our model (see SI). Whereas the Na vacancy formation energy at $\mathrm{x}=2$ and 3 is negligible ( $13 \mathrm{meV})$. Note that at $\mathrm{x}=2, \mathrm{Na}(1)$ and $\mathrm{Na}(2)$ are only partially occupied which guarantees facile $\mathrm{Na}$ transport.

To remove the directional dependence of migration barriers, we define the kinetically resolved activation (KRA) barrier, $\mathrm{E}_{K R A}$ of Equation 2, 


$$
\mathrm{E}_{K R A}=\mathrm{E}_{\text {barrier }}[\mathrm{Na}(1) \leftrightarrow \mathrm{Na}(2)]-\frac{1}{2}\left(\Delta \mathrm{E}_{\text {end }}\right)
$$

where the $\mathrm{E}_{\text {barrier }}[\mathrm{Na}(1) \leftrightarrow \mathrm{Na}(2)]$ is the NEB barrier, ${ }^{39,40}$ and $\Delta \mathrm{E}_{\text {end }}$ is the absolute difference between the computed energies of the initial and final end point structures. The distribution of $\mathrm{E}_{K R A}$ at different configurations of $\mathrm{Na}$ and $\mathrm{Si} / \mathrm{P}$ environments is shown in Figure S1, S2, S3, and Table S1 of the SI.

\section{Local Cluster Expansion Hamiltonian}

The calculated $\mathrm{E}_{K R A}$ are fitted to a local cluster expansion (LCE) Hamiltonian built around a migration unit (see Figure 1d) centered on the $\mathrm{Na}(1)$ site and using a cut-off radius of $5 \AA$. Details of the LCE model and the fitting strategy are given in the SI. The fitted Hamiltonian can be used efficiently to compute migration barriers inside the migration unit at any given $\mathrm{Na} /$ vacancy and Si/P content/configuration. The LCE Hamiltonian includes 1 point, 5 pair, and 1 triplet terms (see Table S3 and Table S4), respectively. The LCE Hamiltonian can reproduce the migration barriers with a RMS error of $\sim \pm 38 \mathrm{meV}$. The robustness of the LCE Hamiltonian was cross-validated using the leave-one out method. Notably, a variability of $\sim \pm 38 \mathrm{meV}$ corresponds to a less than an order of magnitude in diffusivity $( \pm 60 \mathrm{meV}),{ }^{80}$ which is the typical uncertainty of experimental measurements and theoretical calculations for electrode materials. ${ }^{40}$

\section{Kinetic Monte Carlo Simulations}

We implemented a rejection-free kinetic Monte Carlo (kMC) simulation scheme in an in-house-code, as described in Refs. ${ }^{39,40}$. The initial configurations for the kMC were 
generated using the canonical Monte Carlo simulation (based on our previous work where we constructed a global cluster expansion model on the NASICON) ${ }^{19}$ in an $8 \times 8 \times 8$ supercell at $0 \leq x \leq 3$ containing 4,096 distinct Na sites and 3,072 Si/P sites. These structures were generated at $1500 \mathrm{~K}$, and close to the experimental synthesis temperature..$^{17,34,28,41}$ For each of the 11 compositions sampled $(x=0.03,0.3,0.6,0.9$, $1.2,1.5,1.8,2.1,2.4,2.7,2.97), 50$ structural models were generated using the canonical Monte Carlo approach. ${ }^{19}$

We used KMC to evaluate the transport properties of NASICON crystals, including $\mathrm{Na}^{+}$diffusivity, bulk conductivity, Haven's ratio, and correlation factor. These physical quantities are averaged for each of the 50 initial configurations per $\mathrm{Na}$ composition. During the $\mathrm{kMC}$ simulation, only $\mathrm{Na}$ ions can hop while the remaining atoms are frozen. Each kMC simulation included 2,048,000 equilibration steps, followed by $12,288,000$ sampling steps for statistical analysis at 373,473 and $573 \mathrm{~K}$, respectively. In total, we have run 1650 independent kMC simulations (11 compositions $\times 50$ initial configurations $\times 3$ temperatures) with a total of $\sim 14$ million steps per configuration, which totals to approximately 23 billion kMC steps. For investigating the impact of phase separation on ionic transport, we followed the same procedure as above, except the canonical Monte Carlo, equilibrated structures were generated at $573 \mathrm{~K}$, instead of at $1500 \mathrm{~K}$.

\section{Synthesis and $\mathrm{X}$-ray Characterization of $\mathrm{Na}_{1+x} \mathrm{Zr}_{2} \mathrm{Si}_{x} \mathrm{P}_{3-\mathrm{x}} \mathrm{O}_{12}$ Compositions}

Synthesis of $\mathrm{Na}_{1+x} \mathrm{Zr}_{2} \mathrm{Si}_{x} \mathrm{P}_{3-x} \mathrm{O}_{12}$ for $x=1.5$ and $x=2.0$ were carried out using a solgel method with $\mathrm{NaNO}_{3}, \mathrm{NH}_{4} \mathrm{H}_{2} \mathrm{PO}_{4}, \mathrm{ZrO}\left(\mathrm{NO}_{3}\right)_{2} \cdot \mathrm{xH}_{2} \mathrm{O}, \mathrm{Si}\left(\mathrm{OC}_{2} \mathrm{H}_{5}\right)_{4}$ (Tetraethyl orthosilicate/TEOS) and citric acid as precursors followed by carefully optimized 
thermal treatments. Citric acid was first mixed with $300 \mathrm{~mL}$ of ethanol:deionized water $(1: 1)$, at $343 \mathrm{~K}$ for 1 hour. Then a stoichiometric amount of the precursors was introduced to the solution and the temperature was raised to $363 \mathrm{~K}$ for 1.5 hours. The resulting gel was then dried for 8 hours, at $453 \mathrm{~K}$. A first calcination was carried out at $873 \mathrm{~K}$ for 8 hours, followed by second calcination at $1373 \mathrm{~K}$ for 18 hours. For the composition $x=2.4$, a solvent-assisted solid-state reaction method was applied. ${ }^{54}$ Corresponding amounts of $\mathrm{NaNO}_{3}$, and $\mathrm{ZrO}\left(\mathrm{NO}_{3}\right)_{2}$ were dissolved into deionized water. A stoichiometric amount of $\mathrm{Si}\left(\mathrm{OC}_{2} \mathrm{H}_{5}\right)_{4}$ was also added to the solution while stirring. When $\mathrm{Si}\left(\mathrm{OC}_{2} \mathrm{H}_{5}\right)_{4}$ was hydrolyzed, the corresponding amount of $\mathrm{NH}_{4} \mathrm{H}_{2} \mathrm{PO}_{4}$ was added to the system while stirring. The homogeneous aqueous system then changed to a mixture of a colloidal sol and precipitates of complex zirconium oxyphosphate compounds. The whole mixture was dried at $\sim 85^{\circ} \mathrm{C}$. The dried powder was calcined at $\sim 800^{\circ} \mathrm{C}$ for 3 hours. After calcination, a white powder was obtained. The calcined powder was then milled in ethanol with zirconia balls on a milling bench for 48 hours and dried at $\sim 70{ }^{\circ} \mathrm{C}$ for 12 hours. The as-prepared powder (which was just calcinated at $1073 \mathrm{~K}$ ) was then sintered at $\sim 1373 \mathrm{~K}$ for 18 hours to crystallize the phase.

X-Ray diffraction patterns of the obtained white powders were then measured at room temperature using a Bruker D8 diffractometer with copper source, $\left(K_{\alpha 1}=1.54056 \AA\right.$ and $\left.K_{\alpha 2}=1.54439 \AA\right)$, and a step size of $0.021^{\circ}$. Profile matchings were done using WinPLOTR and FullProf software. ${ }^{41}$ For $x=1.5$ the pattern was fitted using the $R \overline{3} c$ space group, ${ }^{18,76,81,82}$ while $\mathrm{x}=2.0$ and $\mathrm{x}=2.4$ were fitted using the $C 2 / c$ space group. ${ }^{41,83}$

Variable temperature impedance measurements of $\mathrm{Na}_{1+x} \mathrm{Zr}_{2} \mathrm{Si}_{x} \mathrm{P}_{3-\mathrm{x}} \mathrm{O}_{12}$ 
For the preparation of impedance measurements, the three samples were cold pressed into $6 \mathrm{~mm}$ pellets and sintered at $\sim 1373 \mathrm{~K}$ for 12 hours. The sintered pellets were then gold-sputtered ( $75 \mathrm{~nm})$, and carbon paper (papyex) was added on each side of the pellet to ensure good contacts for the impedance measurements in the high temperature impedance cell BioLogic $\mathrm{HTSH}-100$. The latter was inserted in high temperature furnace BioLogic HTF-1100 and connected to impedance analyzer BioLogic MTZ-35 with a two-point connection. The frequency range used was from $0.1 \mathrm{~Hz}$ to $30 \mathrm{MHz}$, with an amplitude of $0.02 \mathrm{~V}$. Measurements were recorded every $50 \mathrm{~K}$ from $323 \mathrm{~K}$ to $623 \mathrm{~K}$ (15 minutes soaking each time), and then cooled down every $50 \mathrm{~K}$ from $623 \mathrm{~K}$ to $323 \mathrm{~K}$.

The fitting of Nyquist plot was carried out using ZView software. For $x=1.5$, the equivalent circuit used was based on semicircle phenomena as seen in other reports, ${ }^{28,59,84-86}$ with $\mathrm{R} 1$ representing the contact resistance, parallel of CPE1 and $\mathrm{R} 2$ representing the semi-circle, and initially a CPE2 for the diffusion tail. Since CPE2 has an n-value close to 0.5 , a Warburg element is used to better fit the diffusion tail. Applying the same equivalent circuit for other samples $(x=2.0$ and $x=2.4)$ was not satisfactory, thus a one-phenomena Debye Model for solid electrolyte between two ionically blocking electrodes is used instead. ${ }^{87}$ Schematics of the equivalent circuits are shown in Figure $\mathbf{S 9}$ of SI.

\section{Acknowledgments}

P.C., C.M., A.K.C., E.M., V.S., and J.-N. C. are grateful to the ANR-NRF for the funding of the NRF2019-NRF-ANR073 Na-MASTER project. P.C. and Z.D. acknowledge funding from the National Research Foundation under NRF Fellowship NRFF12-2020- 
0012. T. P. M. was supported by the National Research Foundation (NRF) Singapore through Singapore MIT Alliance for Research and Technology (SMART)'s Low Energy Electronic Systems (LEES) IRG. The computational work was performed on resources of the National Supercomputing Centre, Singapore (https://www.nscc.sg). We thank Dr. Theodosios Famprikis at TUDelft for fruitful discussion.

\section{Authors Contributions}

P.C. designed and supervised the project. Z.D., T.P.M., and P.C. performed the NEB simulations and fitted the local cluster expansion Hamiltonian with discussions with G.S.G. Z.D. developed all the tools for constructing models, Hamiltonian fitting, kinetic Monte Carlo and data analysis. Q.M. and E.M. carried out the synthesis of the NASICON phases, E.M. performed the PXRD, and the impedance measurements. E.M. performed the data analysis of the experimental data under the supervision of J.N. C., V.S. and C. M. Z.D., T.P.M. and P.C. wrote the first draft. Z.D., P.C., G.S.G. and A.K.C. contributed to the initial data analysis of the computed data. All the authors contributed to the discussion and final version of this manuscript.

\section{Conflicts of Interests}

There are no conflicts to declare.

\section{Supplementary information}

The supplementary Information contains details of the density functional theory simulations, nudged elastic band results, kinetic Monte Carlo simulations, AC impedance measurements, equivalent circuits for the analysis of the AC-impedance 
data, and the Arrhenius plot of conductivities vs 1/temperatures of selected NASICON compositions.

\section{Code and Data Availability}

All the computational data associated with this study are freely available at the Git repository https://github.com/caneparesearch/NASICON KMC paper data

\section{References}

1. Goodenough, J. B. \& Park, K.-S. The Li-Ion Rechargeable Battery: A Perspective. J. Am. Chem. Soc. 135, 1167-1176 (2013).

2. Wang, Y. et al. Design principles for solid-state lithium superionic conductors. Nat. Mater. 14, 1026-1031 (2015).

3. He, X., Zhu, Y. \& Mo, Y. Origin of fast ion diffusion in super-ionic conductors. Nat. Commun. 8, 15893 (2017).

4. Bachman, J. C. et al. Inorganic Solid-State Electrolytes for Lithium Batteries: Mechanisms and Properties Governing Ion Conduction. Chem. Rev. 116, 140-162 (2016).

5. Goodenough, J. B. \& Kim, Y. Challenges for Rechargeable Li Batteries. Chem. Mater. 22, 587-603 (2010).

6. Famprikis, T., Canepa, P., Dawson, J. A., Islam, M. S. \& Masquelier, C. Fundamentals of inorganic solid-state electrolytes for batteries. Nat. Mater. 18, 1278-1291 (2019).

7. Deng, Y. et al. Structural and Mechanistic Insights into Fast Lithium-Ion Conduction in $\mathrm{Li}_{4} \mathrm{SiO}_{4}-\mathrm{Li}_{3} \mathrm{PO}_{4}$ Solid Electrolytes. J. Am. Chem. Soc. 137, 9136-9145 (2015).

8. Minafra, N., Culver, S. P., Li, C., Senyshyn, A. \& Zeier, W. G. Influence of the Lithium Substructure on the Diffusion Pathways and Transport Properties of the Thio-LISICON $\mathrm{Li}_{4} \mathrm{Ge}_{1-x} \mathrm{Sn}_{x} \mathrm{~S}_{4}$. Chem. Mater. 31, 3794-3802 (2019).

9. Kamaya, N. et al. A lithium superionic conductor. Nat. Mater. 10, 682-686 (2011).

10. Ong, S. P. et al. Phase stability, electrochemical stability and ionic conductivity of the $\mathrm{Li}_{10 \pm 1} \mathrm{MP}_{2} \mathrm{X}_{12}(\mathrm{M}=\mathrm{Ge}, \mathrm{Si}, \mathrm{Sn}, \mathrm{Al}$ or $\mathrm{P}$, and $\mathrm{X}=\mathrm{O}, \mathrm{S}$ or $\mathrm{Se}$ ) family of superionic conductors. Energy Env. Sci 6, 148-156 (2013).

11. Kuhn, A. et al. A new ultrafast superionic Li-conductor: ion dynamics in $\mathrm{Li}_{11} \mathrm{Si}_{2} \mathrm{PS}_{12}$ and comparison with other tetragonal LGPS-type electrolytes. Phys Chem Chem Phys 16, 14669-14674 (2014).

12. Hori, S. et al. Synthesis, structure, and ionic conductivity of solid solution, $\mathrm{Li}_{10+\delta} \mathrm{M}_{1+\delta} \mathrm{P}_{2-\delta} \mathrm{S}_{12}$ (M = Si, Sn). Faraday Discuss 176, 83-94 (2014).

13. Kato, Y. et al. High-power all-solid-state batteries using sulfide superionic conductors. Nat. Energy 1, 16030 (2016).

14. Culver, S. P. et al. Evidence for a Solid-Electrolyte Inductive Effect in the Superionic Conductor $\mathrm{Li}_{10} \mathrm{Ge}_{1-x} \mathrm{Sn}_{x} \mathrm{P}_{2} \mathrm{~S}_{12}$. J. Am. Chem. Soc. 142, 21210-21219 (2020). 
15. Zhou, L. et al. An Entropically Stabilized Fast-Ion Conductor: $\mathrm{Li}_{3.25}\left[\mathrm{Si}_{0.25} \mathrm{P}_{0.75}\right] \mathrm{S}_{4}$. Chem. Mater. 31, 7801-7811 (2019).

16. Minami, T., Hayashi, A. \& Tatsumisago, M. Recent progress of glass and glass-ceramics as solid electrolytes for lithium secondary batteries. Solid State Ion. 177, 2715-2720 (2006).

17. Hong, H. Y.-P. Crystal structures and crystal chemistry in the system $\mathrm{Na}_{1+x} \mathrm{Zr}_{2} \mathrm{Si}_{x} \mathrm{P}_{3-\mathrm{x}} \mathrm{O}_{12}$. Mater. Res. Bull. 11, 173-182 (1976).

18. Goodenough, J. B., Hong, H. Y.-P. \& Kafalas, J. A. Fast $\mathrm{Na}^{+}$-ion transport in skeleton structures. Mater. Res. Bull. 11, 203-220 (1976).

19. Deng, Z. et al. Phase Behavior in Rhombohedral NaSiCON Electrolytes and Electrodes. Chem. Mater. 32, 7908-7920 (2020).

20. Gao, Y. et al. Classical and Emerging Characterization Techniques for Investigation of Ion Transport Mechanisms in Crystalline Fast Ionic Conductors. Chem. Rev. 120, 5954-6008 (2020).

21. Zhang, Z. et al. New horizons for inorganic solid state ion conductors. Energy Environ. Sci. 11, 1945-1976 (2018).

22. Dawson, J. A., Canepa, P., Famprikis, T., Masquelier, C. \& Islam, M. S. Atomic-Scale Influence of Grain Boundaries on Li-Ion Conduction in Solid Electrolytes for All-Solid-State Batteries. J. Am. Chem. Soc. 140, 362-368 (2018).

23. Marcolongo, A. \& Marzari, N. Ionic correlations and failure of Nernst-Einstein relation in solid-state electrolytes. Phys. Rev. Mater. 1, 025402 (2017).

24. He, X., Zhu, Y., Epstein, A. \& Mo, Y. Statistical variances of diffusional properties from ab initio molecular dynamics simulations. Npj Comput. Mater. 4, 18 (2018).

25. Haarmann, L. \& Albe, K. From ionic to superionic conductivity: The influence of cation order on sodium diffusion in $\mathrm{Na}_{3} \mathrm{Zr}_{2} \mathrm{Si}_{2} \mathrm{PO}_{12}$. Solid State Ion. 363, 115604 (2021).

26. Guin, M. \& Tietz, F. Survey of the transport properties of sodium superionic conductor materials for use in sodium batteries. J. Power Sources 273, 1056-1064 (2015).

27. Lalère, F. et al. An all-solid state NASICON sodium battery operating at $200{ }^{\circ} \mathrm{C}$. J. Power Sources 247, 975-980 (2014).

28. Ma, Q. et al. Scandium-Substituted $\mathrm{Na}_{3} \mathrm{Zr}_{2}\left(\mathrm{SiO}_{4}\right)_{2}\left(\mathrm{PO}_{4}\right)$ Prepared by a Solution-Assisted Solid-State Reaction Method as Sodium-Ion Conductors. Chem. Mater. 28, 4821-4828 (2016).

29. Ouyang, B. et al. Synthetic accessibility and stability rules of NASICONs. Nat. Commun. 12, 5752 (2021).

30. Boilot, J. P., Collin, G. \& Colomban, Ph. Relation structure-fast ion conduction in the NASICON solid solution. J. Solid State Chem. 73, 160-171 (1988).

31. Boilot, J. P., Collin, G. \& Colomban, P. Crystal structure of the true nasicon: $\mathrm{Na}_{3} \mathrm{Zr}_{2} \mathrm{Si}_{2} \mathrm{PO}_{12}$. Mater. Res. Bull. 22, 669-676 (1987).

32. Zhang, Z. et al. Correlated Migration Invokes Higher $\mathrm{Na}^{+}-$Ion Conductivity in NaSICONType Solid Electrolytes. Adv. Energy Mater. 9, 1902373 (2019).

33. Deng, Y. et al. Crystal Structures, Local Atomic Environments, and Ion Diffusion Mechanisms of Scandium-Substituted Sodium Superionic Conductor (NASICON) Solid Electrolytes. Chem. Mater. 30, 2618-2630 (2018).

34. Zou, Z. et al. Relationships Between $\mathrm{Na}^{+}$Distribution, Concerted Migration, and Diffusion Properties in Rhombohedral NASICON. Adv. Energy Mater. 10, 2001486 (2020).

35. Henkelman, G., Uberuaga, B. P. \& Jónsson, H. A climbing image nudged elastic band method for finding saddle points and minimum energy paths. J. Chem. Phys. 113, 99019904 (2000). 
36. Sun, J., Ruzsinszky, A. \& Perdew, J. P. Strongly Constrained and Appropriately Normed Semilocal Density Functional. Phys. Rev. Lett. 115, 036402 (2015).

37. Chen, T., Sai Gautam, G. \& Canepa, P. Ionic Transport in Potential Coating Materials for Mg Batteries. Chem. Mater. 31, 8087-8099 (2019).

38. Du, Y. A. \& Holzwarth, N. A. W. Mechanisms of $\mathrm{Li}^{+}$diffusion in crystalline $\mathrm{Y}$ - and $\beta-\mathrm{Li}_{3} \mathrm{PO}_{4}$ electrolytes from first principles. Phys. Rev. B 76, 174302 (2007).

39. Van der Ven, A., Ceder, G., Asta, M. \& Tepesch, P. D. First-principles theory of ionic diffusion with nondilute carriers. Phys. Rev. B 64, 184307 (2001).

40. Van der Ven, A., Deng, Z., Banerjee, S. \& Ong, S. P. Rechargeable Alkali-lon Battery Materials: Theory and Computation. Chem. Rev. 120, 6977-7019 (2020).

41. Deng, Y. et al. Crystal Structures, Local Atomic Environments, and Ion Diffusion Mechanisms of Scandium-Substituted Sodium Superionic Conductor (NASICON) Solid Electrolytes. Chem. Mater. 30, 2618-2630 (2018).

42. Hayashi, K., Shima, K. \& Sugiyama, F. A Mixed Aqueous/Aprotic Sodium/Air Cell Using a NASICON Ceramic Separator. J. Electrochem. Soc. 160, A1467-A1472 (2013).

43. Park, H., Jung, K., Nezafati, M., Kim, C.-S. \& Kang, B. Sodium lon Diffusion in Nasicon $\left(\mathrm{Na}_{3} \mathrm{Zr}_{2} \mathrm{Si}_{2} \mathrm{PO}_{12}\right)$ Solid Electrolytes: Effects of Excess Sodium. ACS Appl. Mater. Interfaces 8, 27814-27824 (2016).

44. Lunghammer, S. et al. Fast $\mathrm{Na}$ ion transport triggered by rapid ion exchange on local length scales. Sci. Rep. 8, 11970 (2018).

45. Naqash, S., Tietz, F., Yazhenskikh, E., Müller, M. \& Guillon, O. Impact of sodium excess on electrical conductivity of $\mathrm{Na}_{3} \mathrm{Zr}_{2} \mathrm{Si}_{2} \mathrm{PO}_{12+x} \mathrm{Na}_{2} \mathrm{O}$ ceramics. Solid State lon. 336, 57-66 (2019).

46. Morgan, B. J. Mechanistic Origin of Superionic Lithium Diffusion in Anion-Disordered $\mathrm{Li}_{6} \mathrm{PS}_{5} \mathrm{X}$ Argyrodites. Chem. Mater. 33, 2004-2018 (2021).

47. Morgan, B. J. Lattice-geometry effects in garnet solid electrolytes: a lattice-gas Monte Carlo simulation study. R. Soc. Open Sci. 4, 170824 (2017).

48. Masquelier, C. \& Croguennec, L. Polyanionic (Phosphates, Silicates, Sulfates) Frameworks as Electrode Materials for Rechargeable Li (or Na) Batteries. Chem. Rev. 113, 6552-6591 (2013).

49. Xiao, Y. et al. Lithium Oxide Superionic Conductors Inspired by Garnet and NASICON Structures. Adv. Energy Mater. 2101437 (2021) doi:10.1002/aenm.202101437.

50. Rudolf, P. R., Clearfield, A. \& Jorgensen, J. D. A time of flight neutron powder rietveld refinement study at elevated temperature on a monoclinic near-stoichiometric NASICON. J. Solid State Chem. 72, 100-112 (1988).

51. Bukun, N. G. Superionic transitions in NASICON-type solid electrolytes. Ionics 2, 63-68 (1996).

52. von Alpen, U., Bell, M. F. \& Wichelhaus, W. Phase transition in nasicon $\left(\mathrm{Na}_{3} \mathrm{Zr}_{2} \mathrm{Si}_{2} \mathrm{PO}_{12}\right)$. Mater. Res. Bull. 14, 1317-1322 (1979).

53. Jolley, A. G., Taylor, D. D., Schreiber, N. J. \& Wachsman, E. D. Structural Investigation of Monoclinic-Rhombohedral Phase Transition in $\mathrm{Na}_{3} \mathrm{Zr}_{2} \mathrm{Si}_{2} \mathrm{PO}_{12}$ and Doped NASICON. J. Am. Ceram. Soc. 98, 2902-2907 (2015).

54. Ma, Q. et al. Room temperature demonstration of a sodium superionic conductor with grain conductivity in excess of $0.01 \mathrm{~S} \mathrm{~cm}^{-1}$ and its primary applications in symmetric battery cells. J. Mater. Chem. A 7, 7766-7776 (2019).

55. Zhu, D., Luo, F., Xie, Z. \& Zhou, W. Preparation and characteristic of NASICON ceramics. Rare Met. 25, 39-42 (2006). 
56. Chen, D., Luo, F., Zhou, W. \& Zhu, D. Influence of $\mathrm{Nb}^{5+}, \mathrm{Ti}^{4+}, \mathrm{Y}^{3+}$ and $\mathrm{Zn}^{2+}$ doped $\mathrm{Na}_{3} \mathrm{Zr}_{2} \mathrm{Si}_{2} \mathrm{PO}_{12}$ solid electrolyte on its conductivity. J. Alloys Compd. 757, 348-355 (2018).

57. Traversa, E., Aono, H., Sadaoka, Y. \& Montanaro, L. Electrical properties of sol-gel processed NASICON having new compositions. Sens. Actuators B Chem. 65, 204-208 (2000).

58. Ladenstein, L. et al. On the Dependence of Ionic Transport on Crystal Orientation in Nasicon-Type Solid Electrolytes. ECS Meet. Abstr. MA2020-02, 946-946 (2020).

59. Grady, Z. M., Tsuji, K., Ndayishimiye, A., Hwan-Seo, J. \& Randall, C. A. Densification of a Solid-State NASICON Sodium-Ion Electrolyte Below $400{ }^{\circ} \mathrm{C}$ by Cold Sintering With a Fused Hydroxide Solvent. ACS Appl. Energy Mater. 3, 4356-4366 (2020).

60. Perthuis, H. \& Colomban, Ph. Sol-gel routes leading to nasicon ceramics. Ceram. Int. 12, 39-52 (1986).

61. Hayashi, K., Shima, K. \& Sugiyama, F. A Mixed Aqueous/Aprotic Sodium/Air Cell Using a NASICON Ceramic Separator. J. Electrochem. Soc. 160, A1467-A1472 (2013).

62. Bloembergen, N., Purcell, E. M. \& Pound, R. V. Relaxation Effects in Nuclear Magnetic Resonance Absorption. Phys. Rev. 73, 679-712 (1948).

63. Ciucci, F. Modeling electrochemical impedance spectroscopy. Curr. Opin. Electrochem. 13, 132-139 (2019).

64. Kumar, P. P. \& Yashonath, S. A Full Interionic Potential for $\mathrm{Na}_{1+x} \mathrm{Zr}_{2} \mathrm{Si}_{x} \mathrm{P}_{3-\mathrm{x}} \mathrm{O}_{12}$ Superionic Conductors. J. Am. Chem. Soc. 124, 3828-3829 (2002).

65. Roy, S. \& Kumar, P. P. Influence of Cationic ordering on ion transport in NASICONs: Molecular dynamics study. Solid State Ion. 253, 217-222 (2013).

66. Roy, S. \& Padma Kumar, P. Influence of Si/P ordering on $\mathrm{Na}+$ transport in NASICONs. Phys. Chem. Chem. Phys. 15, 4965 (2013).

67. Mo, Y., Ong, S. P. \& Ceder, G. First Principles Study of the $\mathrm{Li}_{10} \mathrm{GeP}_{2} \mathrm{~S}_{12}$ Lithium Super Ionic Conductor Material. Chem. Mater. 24, 15-17 (2012).

68. Zhou, M. \& Ahmad, A. Synthesis, processing and characterization of nasicon solid electrolytes for $\mathrm{CO}_{2}$ sensing applications. Sens. Actuators B Chem. 122, 419-426 (2007).

69. Singh, B. et al. A chemical map of NaSICON electrode materials for sodium-ion batteries. J. Mater. Chem. A 9, 281-292 (2021).

70. Wang, Z. et al. Phase Stability and Sodium-Vacancy Orderings in a NaSICON Electrode. ArXiv210906997 Cond-Mat (2021).

71. Jolley, A. G., Cohn, G., Hitz, G. T. \& Wachsman, E. D. Improving the ionic conductivity of NASICON through aliovalent cation substitution of $\mathrm{Na}_{3} \mathrm{Zr}_{2} \mathrm{Si}_{2} \mathrm{PO}_{12}$. Ionics 21, 3031-3038 (2015).

72. Miyajima, $\mathrm{Y}$. Solubility range and ionic conductivity of large trivalent ion doped $\mathrm{Na}_{1+x} \mathrm{M}_{x} \mathrm{Zr}_{2-x} \mathrm{P}_{3} \mathrm{O}_{12}(\mathrm{M}: \mathrm{In}, \mathrm{Yb}, \mathrm{Er}, \mathrm{Y}, \mathrm{Dy}, \mathrm{Tb}, \mathrm{Gd})$ solid electrolytes. Solid State Ion. 124, 201-211 (1999).

73. Samiee, M. et al. Divalent-doped $\mathrm{Na}_{3} \mathrm{Zr}_{2} \mathrm{Si}_{2} \mathrm{PO}_{12}$ natrium superionic conductor: Improving the ionic conductivity via simultaneously optimizing the phase and chemistry of the primary and secondary phases. J. Power Sources 347, 229-237 (2017).

74. Takahashi, T., Kuwabara, K. \& Shibata, M. Solid-state ionics - conductivities of $\mathrm{Na}^{+}$ion conductors based on NASICON. Solid State Ion. 1, 163-175 (1980).

75. Shannon, R. D. Revised effective ionic radii and systematic studies of interatomic distances in halides and chalcogenides. Acta Crystallogr. Sect. A 32, 751-767 (1976).

76. Park, H., Kang, M., Park, Y.-C., Jung, K. \& Kang, B. Improving ionic conductivity of Nasicon $\left(\mathrm{Na}_{3} \mathrm{Zr}_{2} \mathrm{Si}_{2} \mathrm{PO}_{12}\right)$ at intermediate temperatures by modifying phase transition behavior. J. Power Sources 399, 329-336 (2018). 
77. Kresse, G. \& Furthmüller, J. Efficient iterative schemes for ab initio total-energy calculations using a plane-wave basis set. Phys. Rev. B 54, 11169-11186 (1996).

78. Kresse, G. \& Furthmüller, J. Efficiency of ab-initio total energy calculations for metals and semiconductors using a plane-wave basis set. Comput. Mater. Sci. 6, 15-50 (1996).

79. Gorai, P., Famprikis, T., Singh, B., Stevanović, V. \& Canepa, P. Devil is in the Defects: Electronic Conductivity in Solid Electrolytes. Chem. Mater. 33, 7484-7498 (2021).

80. Chen, T., Sai Gautam, G. \& Canepa, P. Ionic Transport in Potential Coating Materials for Mg Batteries. Chem. Mater. 31, 8087-8099 (2019).

81. Boilot, J. P., Salanié, J. P., Desplanches, G. \& Le Potier, D. Phase transformation in $\mathrm{Na}_{1+x} \mathrm{Si}_{x} \mathrm{Zr}_{2} \mathrm{P}_{3-\mathrm{x}} \mathrm{O}_{12}$ compounds. Mater. Res. Bull. 14, 1469-1477 (1979).

82. Ignaszak, A., Pasierb, P., Gajerski, R. \& Komornicki, S. Synthesis and properties of Nasicon-type materials. Thermochim. Acta 426, 7-14 (2005).

83. Wang, X., Chen, J., Mao, Z. \& Wang, D. Effective resistance to dendrite growth of NASICON solid electrolyte with lower electronic conductivity. Chem. Eng. J. 427, 130899 (2022).

84. Bohnke, O. Conductivity measurements on nasicon and nasicon-modified materials. Solid State Ion. 122, 127-136 (1999).

85. Liu, S. et al. Ce-Substituted Nanograin $\mathrm{Na}_{3} \mathrm{Zr}_{2} \mathrm{Si}_{2} \mathrm{PO}_{12}$ Prepared by LF-FSP as SodiumIon Conductors. ACS Appl. Mater. Interfaces 12, 3502-3509 (2020).

86. Naqash, S., Ma, Q., Tietz, F. \& Guillon, O. $\mathrm{Na}_{3} \mathrm{Zr}_{2}\left(\mathrm{SiO}_{4}\right)_{2}\left(\mathrm{PO}_{4}\right)$ prepared by a solutionassisted solid state reaction. Solid State Ion. 302, 83-91 (2017).

87. Huggins, R. A. Simple method to determine electronic and ionic components of the conductivity in mixed conductors a review. lonics 8, 300-313 (2002). 


\section{Supplementary Files}

This is a list of supplementary files associated with this preprint. Click to download.

- nasiconkmcSIforsubmission.pdf 